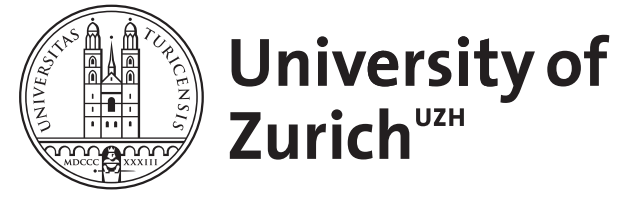

\title{
The evolution of food sharing in primates
}

Jaeggi, A V ; van Schaik, C P

\begin{abstract}
The aim of this study is to explain the occurrence of food sharing across primates. Defined as the unresisted transfer of food, evolutionary hypotheses have to explain why possessors should relinquish food rather than keep it. While sharing with offspring can be explained by kin selection, explanations for sharing among unrelated adults are more controversial. Here we test the hypothesis that sharing occurs with social partners that have leverage over food possessors due to the opportunity for partner choice in other contexts. Thus, we predict that possessors should relinquish food to potential mates or allies, who could provide or withhold matings or coalitionary support in the future. We used phylogenetic analyses based on both maximum likelihood and Bayesian approaches in a sample of 68 primate species to test these predictions. The analyses strongly indicate that (1) sharing with offspring is predicted by the relative processing difficulty of the diet, as measured by the degree of extractive foraging, but not overall diet quality, (2) food sharing among adults only evolved in species already sharing with offspring, regardless of diet, and (3) male-female sharing co-evolved with the opportunity for female mate choice and sharing within the sexes with coalition formation. These results provide comparative support for the hypothesis that sharing is "traded" for matings and coalitionary support in the sense that these services are statistically associated and can thus be selected for. Based on this, we predict that sharing should occur in any species with opportunities for partner choice.
\end{abstract}

DOI: https://doi.org/10.1007/s00265-011-1221-3

Posted at the Zurich Open Repository and Archive, University of Zurich

ZORA URL: https://doi.org/10.5167/uzh-57055

Journal Article

Accepted Version

Originally published at:

Jaeggi, A V; van Schaik, C P (2011). The evolution of food sharing in primates. Behavioral Ecology and Sociobiology, 65(11):2125-2140.

DOI: https://doi.org/10.1007/s00265-011-1221-3 


\section{Behavioral}

Ecology

and Sociobiology

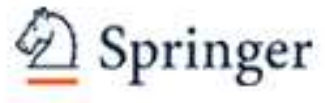

\section{The evolution of food sharing in primates}

\begin{tabular}{|r|l|}
\hline Journal: & Behavioral Ecology and Sociobiology \\
\hline Manuscript ID: & BES-11-0037.R2 \\
\hline Manuscript Type: & Original Paper \\
\hline Author: & n/a \\
\hline Complete List of Authors: & $\begin{array}{l}\text { Jaeggi, Adrian; University of Zurich, Anthropological Institute \& } \\
\text { Museum; University of Zurich, Research Priority Program in Ethics; } \\
\text { University of California Santa Barbara, Integrative Anthropological } \\
\text { vaiences Schaik, Carel; University of Zurich, Anthropological Insitute \& } \\
\text { Museum }\end{array}$ \\
\hline \hline Keywords: & $\begin{array}{l}\text { Coalitions, Cooperation, Food sharing, Mate choice, Provisioning, } \\
\text { Reciprocal altruism, Social bonds }\end{array}$ \\
\hline
\end{tabular}




\section{The evolution of food sharing in primates}

2

3 ADRIAN V. JAEGGI ${ }^{1,2,3} *$ \& CAREL P. VAN SCHAIK ${ }^{1}$

4

$5{ }^{1}$ Anthropological Institute and Museum, University of Zurich, Winterthurerstr. 190,

68057 Zurich, Switzerland

$7 \quad{ }^{2}$ Research Priority Program in Ethics, University of Zurich, Zollikerstr. 117, 8008

8 Zurich, Switzerland

$9{ }^{3}$ Integrative Anthropological Sciences, University of California Santa Barbara, Santa

10 Barbara, CA 93106-3210, USA

$11 *$ corresponding author

12

13 Author contact:

14 e-mail: ajaeggi@anth.ucsb.edu

15 Phone: +18054558587

16

17

18

19 Key words: coalitions, cooperation, food sharing, mate choice, reciprocal altruism,

20 social bonds

21

22

23

24 


\section{Abstract}

The aim of this study is to explain the occurrence of food sharing across

27 primates. Defined as the unresisted transfer of food, evolutionary hypotheses have to explain why possessors should relinquish food rather than keep it. While sharing with offspring can be explained by kin selection, explanations for sharing among unrelated

30 adults are controversial. Here we test the hypothesis that sharing occurs with social partners that have leverage over food possessors due to the opportunity for partner choice in other contexts. Thus, we predict that possessors should relinquish food to potential mates or allies, who could provide or withhold matings or coalitionary support

34 in the future. We used phylogenetic analyses based on both maximum likelihood and Bayesian approaches in a sample of 68 primate species to test these predictions. The analyses strongly indicate that (i) sharing with offspring is predicted by the relative processing difficulty of the diet, as measured by the degree of extractive foraging, but not overall diet quality, (ii) food sharing among adults only evolved in species already sharing with offspring, regardless of diet, and that (iii) male-female sharing co-evolved with the opportunity for female mate choice and sharing within the sexes with coalition formation. These results provide comparative support for the hypothesis that sharing is "traded" for matings and coalitionary support in the sense that these services are statistically associated and can thus be selected for. Based on this, we predict that

44 sharing should occur in any species with opportunities for partner choice. 


\section{Introduction}

Food sharing (henceforth: sharing) is defined as the unresisted transfer of food

from one food-motivated individual, the "possessor", to another, the "recipient"

(Feistner and McGrew 1989). We define possession as being in physical contact with

the food and this definition excludes transfers in which there was no clear possession, such as collecting scraps from the vicinity of a feeding individual. Thus, it should be clear that our trait of interest is that possessors voluntarily (as far as we can infer) relinquish food to the benefit of the recipient, which requires an evolutionary explanation. Sharing with related offspring is relatively common in various animal taxa (Clutton-Brock 1991; Ydenberg 1994; Brown et al. 2004; Mas and Kölliker 2008;

Rapaport and Brown 2008) and its evolution can be explained by kin selection (Hamilton 1964). In contrast, sharing among unrelated adults is far less common and the benefits of sharing to possessors may vary in different taxa (Stevens and Gilby 2004). It is therefore surprising that among non-human primates, non-kin sharing is relatively common (Feistner and McGrew 1989; Brown et al. 2004). harassment and reciprocal exchange (Feistner and McGrew 1989; Brown et al. 2004) ${ }^{1}$. While the two hypotheses are not mutually exclusive (Stevens and Gilby 2004; Gilby 2006), harassment is often assumed to be the more parsimonious explanation because it does not evoke delayed benefits but describes sharing as a mutualistic interaction

69 (Stevens and Stephens 2002; Clutton-Brock 2009). Furthermore, the fact that the vast majority of transfers in primates are passive ( $>95 \%$ in most species, reviewed by Jaeggi et al. 2010a) also supports the notion that it is induced by harassment. According to

\footnotetext{
${ }^{1}$ Other hypotheses explaining sharing in humans or other animals such as costly signaling are not discussed here because there is no convincing evidence supporting them in primates
} 
72 Stevens and Stephens' (2002) harassment model possessors share to avoid the costs (in

73 terms of decreased consumption rate) inflicted by beggars. Similarly, tolerated theft

74 models explain sharing by the differential marginal value of food to increasingly sated

75 possessors vs. continually hungry beggars in light of the constant costs of defending

76 food (Blurton Jones 1984; Blurton Jones 1987). In both models, the possessors'

77 cost/benefit ratio is manipulated by beggars in such a way that sharing is the most

78 beneficial option.

Although the harassment model provides a strong and simple explanation for

80 why sharing occurs at all, an additional explanation may sometimes be warranted to

81 explain the specific possessor-recipient combinations seen to share food and the

82 distribution of sharing across species. For instance, some troops of olive baboons

83 (Papio anubis) hunt and eat meat, possession is biased towards dominant males and

84 sharing is rare, suggesting that the costs of defending food are small for dominant

85 possessors (Strum 1975; Strum 1981). Surprisingly, the few instances of sharing do not

86 occur with other males but rather with females, who are much smaller than males and

87 should be less costly to rebuff. Rather than the harassment costs inflicted on males, what

88 seems to be the decisive factor are the social costs of rebuffing females: sharing almost

89 exclusively occurs with consort partners or, if outside of consorts, among males and

90 females "with previously established affiliative bond" (Strum 1981, p. 278, emphasis

91 added). Hence, by not sharing, the male might risk to upset and possibly lose his consort

92 or long-term social partner, both of which could decrease his mating chances and thus

93 ultimately his reproductive success. These social costs have actually been shown in

94 orangutans, where males share easily defendable food with females because females 
may end the association by seeking out other males if the male does not comply, thus eliminating his mating opportunities (van Noordwijk and van Schaik 2009).

The idea of social costs has long been acknowledged in human food sharing, where stingy individuals may be excluded from future shares (Hill and Kaplan 1993; Gurven 2004), and "when weighing the costs of defending a resource against tolerated theft, therefore, an owner can be expected to include in the costs the likelihood of any forgone future favors" (Cashdan 1997, p. 69). Hence, harassment-induced sharing is inextricably linked to the social relationships of the individuals involved. Even if primates cannot consciously represent future costs, natural selection should thus favor the respective emotional proxies (Schino and Aureli 2009) to make possessors respond more to the harassment of an important social partner.

This indicates that harassment-induced sharing does not preclude reciprocal exchange as long as it can be selective. Indeed, there is some good evidence among chimpanzees that sharing is usually directed towards important social partners. For instance, dominant males at Mahale will try to gain possession of carcasses after a successful hunt and only their long-term allies are allowed in the begging cluster, where they can get a share of the meat (Kawanaka 1982; Nishida et al. 1992). Long-term allies are more likely than other males to provide the dominant male with grooming or coalitionary support in the future, having already done so in the past. This selective sharing with important social partners thus leads to a statistical association with other social services and can explain why almost every statistical test for reciprocal exchange among chimpanzees found some evidence for it (e.g. de Waal 1989; de Waal 1997; Gilby 2006; Mitani 2006; Gomes and Boesch 2009; Jaeggi et al. 2010c). 
Although many are reluctant to embrace the idea of reciprocal exchange among

119 animals (e.g. Clutton-Brock 2009) because of the supposed cognitive constraints

120 (Stevens and Hauser 2004), there is a lot of good evidence for a statistical contingency

121 between favors given and received over long time periods (see, e.g. Watts 2002; Schino

122 2007; Gomes et al. 2009; and food sharing references mentioned above). Such

123 exchanges do not have to be regulated by sophisticated cognitive mechanisms but could

124 reflect social bonds with loose emotional (rather than strict mental) score-keeping, just

125 like friendships in humans (Trivers 1971; Silk 2002; Schino and Aureli 2009). Such

126 bonds are formed in many primate species (Cords 1997; Tomasello and Call 1997; Silk

127 2002; Massen et al. 2010) and are sufficient to account for the loose exchange of low-

128 cost altruistic acts common in primate groups (Schino and Aureli 2009).

129 In sum, the aim of this paper is to trace the evolution of food sharing in primates

130 and explain its occurrence across species. We will first test hypotheses that explain the

131 evolution of sharing with offspring, and then sharing among (unrelated) adults. In

132 particular, we test the hypothesis that sharing among adults coevolved with

133 opportunities for partner choice, giving recipients leverage over possessors because they

134 can withhold future services such as mating or coalitionary support, thus inflicting

135 social costs on stingy possessors. By selectively tolerating harassment from recipients

136 who have such leverage, possessors avoid these social costs which leads to a statistical

137 association of favors given and received over longer time periods and this selective

138 tolerance can thus be favored by natural selection. While many studies have tested for

139 reciprocal exchange within a species, we take a comparative approach and test for the

140 correlated evolution of sharing with conditions that favor reciprocal exchange in a large

141 sample of primates. In particular, we suggest that the opportunity for female mate 
142 choice can account for male-female sharing and coalition formation for sharing within

143 the sexes. This is the first study to conduct a phylogenetically controlled analysis on the

144 conditions associated with food sharing in primates and thus extends intraspecific

145 analyses in important ways that allow predictions about species not included in this

146 sample.

147 Methods

148 Comparative sample

149 We compiled an exhaustive list of 173 references related to sharing in primates

150 (Table 1). Species were included in the analyses if either sharing had been reported or if

151 no sharing had been reported despite considerable study effort (at least 10 behavioral

152 studies on the species listed in ISI Web of Science by end of 2010). Sharing with

153 offspring and among adults was quantified as absent (0), present (1: mentioned occasionally) or common (2: more than one study explicitly addressing sharing) or present (1) or absent (0), depending on the statistical method (see Comparative

156 Analyses). Furthermore, sharing between particular sex combinations of adults, namely

157 from males to females, among males and among females, was scored as present or

158 absent. Sharing from females to males was too rare to test and there is no clear

159 hypothesis associated with it. If the only reported sharing occurred in artificial

160 experimental settings but never in naturalistic conditions and it was not clear whether

161 the reported sharing was tolerated or resisted it was not counted as present (since the

162 trait of interest is tolerated sharing). In particular, this concerns sharing in Saimiri

163 sciureus (Fragaszy and Mason 1983; Stevens 2004) and adult Hylobates lar (Schessler

164 and Nash 1977; Nettelbeck 1998). Thus, a total of 68 primate species could be included

165 in the comparative sample (Table 1, Figure 1). 
$\underline{\text { Predictor variables }}$

In the following section we elaborate the hypotheses explaining the evolution of

170 sharing with offspring as well as sharing among adults in general and within specific

sex combinations, and provide predictor variables to test them in a comparative analysis. It should be noted that variables in a comparative study, where the units of analysis are species, are necessarily much cruder than in within species analysis where we can correlate one detailed behavioral measure with another on the level of individuals (e.g. A sharing food with B, with B providing coalitionary support to A).

Thus, rather than describing a precise behavioral mechanism, we can identify the conditions under which natural selection could install such mechanisms. While the variables may not be ideal, comparative analyses are unlikely to produce false positives and have the additional benefit that they allow us to infer the presence of certain traits in

180 other species, given the conditions found to be predictive in this sample, which can

181 subsequently be confirmed with more detailed study.

\section{$182 \quad$ Sharing with offspring} relinquishing food are relatively low for parents or helpers and the benefits of receiving

185 food are high for offspring. This should be the case when there is high variation and

186 differential skill in food acquisition, or, in other words, when adults regularly acquire

187 food which the offspring cannot yet acquire themselves. As transfers of such food items do not only provide the offspring with additional nutrients but also with information about the affordances of otherwise unreachable items, this has also been named the 
190 informational hypothesis (Brown et al. 2004). Here we operationalize the required skill

191 in food acquisition by the degree of extractive foraging, as defined by Gibson (1986).

192 Species were thus classified as non-extractive foragers (0), un-skilled/specialized

193 extractive foragers (1) and skilled extractive foragers (2). In contrast to Gibson (1986)

194 we classified Pongo as skilled extractive foragers since there is now good evidence for

195 complex extractive foraging skills such as tool-use (van Schaik et al. 1996) and that

196 skills are acquired through prolonged periods of social and individual learning in both

197 orangutan species (Forss et al. 2009; Jaeggi et al. 2010b).

198 Furthermore, it has been proposed that adults may use food provisioning to

199 increase growth rates and facilitate weaning and that sharing with offspring should thus

200 specifically target high quality food items. This is known as the nutritional hypothesis

201 (Brown et al. 2004). Thus, we predicted that sharing with offspring should be more common in species with high quality diets, possibly in interaction with extractive foraging. We operationalized this by using a diet quality index (DQI), as defined by Fish

204 \& Lockwood (2003):

$$
\mathrm{DQI}=0.33 \mathrm{~L}+0.67 \mathrm{~F}+\mathrm{M}
$$

where $\mathrm{L}, \mathrm{F}$, and $\mathrm{M}$ are the percentages of time spent foraging for leaves and other vegetative plant parts, fruit (including gum and flowers), and meat (indeed, any animal matter), respectively. The possible range of DQI values is $0.33-1$. The values were

209 obtained directly from Fish \& Lockwood (2003) or calculated from Rowe (1996). If

210 numbers were unavailable for a species, the value of the sister species was used.

\section{Sharing among adults (general)}

212 Our first prediction, inspired by classic ethology is that sharing among adults is

213 derived from sharing with offspring, the same way courtship feeding in birds is derived 
214 from chick provisioning (Tinbergen 1952; Lorenz 1965). Indeed, most affiliative

215 behaviors and their proximate regulations are derived from the mother-offspring context

216 (Hrdy 1999; Hrdy 2009) and the presence of sharing with offspring may thus be a

217 precondition or a constraint on the evolution of sharing among adults.

218 Furthermore, as in sharing with offspring, one would predict sharing among

219 adults to occur whenever the cost/benefit-ratio of transferring the food item at stake is

220 favorable, in particular when food items are large and/or highly valuable and when

221 possession is biased and/or unpredictable (Kaplan and Hill 1985). Indeed, most sharing

222 occurs with items that fulfill these criteria, such as meat (e.g. Strum 1975; Perry and

223 Rose 1994; Utami and van Hooff 1997; Stanford 1999; Mitani and Watts 2001;

224 Hohmann and Fruth 2008; Gomes and Boesch 2009) or large fruits (e.g. White 1994;

225 Hockings et al. 2007; D. Watts, pers.comm.). However, sharing also occasionally occurs

226 with easily defendable or accessible food items such as small fruits (Slocombe and

227 Newton-Fisher 2005; van Noordwijk and van Schaik 2009) or plentiful browse

228 (Kavanagh 1972) suggesting that the social relationships of the involved individuals

229 were more important than the food items at stake. Nonetheless, it is possible that diet

230 acts as a constraint on the evolution of adult sharing and we thus included the same diet

231 variables used to explain sharing with offspring, i.e. extractive foraging and diet quality

232 index in the analyses.

233 Sharing from males to females - Female mate choice and pair bonds ("Food for sex")

234 Popularly known as the meat-for-sex hypothesis, it is sometimes assumed that

235 males "buy" immediate mating benefits with high quality food. However, in

236 chimpanzees contingent exchanges of food and matings (in the short term) are rare and

237 males also commonly share with lactating females (reviewed by Gilby et al. 2010). 
238 Sharing is therefore better seen as an expression of long-term investment in social

239 relationships that might eventually relate to higher mating success, possibly because not

240 sharing might lead to lower mating success. Thus the hypothesis can be formulated

241 more generally: Whenever females can exert mate choice, males should allow females

242 to take food in order to maintain their chances of mating with the female in the future

243 (Strum 1981; Gomes and Boesch 2009; van Noordwijk and van Schaik 2009). In more

244 proximate terms, it could be said that in the presence of female choice, males and

245 females may form affiliative social bonds, one expression of which is the sharing of

246 food. Hence we predict that female mate choice favors sharing from males to females.

247 How do we operationalize female choice? First of all, we have to make clear that

248 we are interested in behavioral female choice (and not cryptic female choice), wherein

249 females initiate or terminate association, consortship or mating (Clutton-Brock and

250 McAuliffe 2009), because the consequences of these behaviors are actually experienced

251 by males and can thus shape their own behavior. Ideally, we would use a direct measure

252 of expressed female choice such as the percentage of female-initiated matings or refused

253 matings. However, such detailed behavioral data are not available for a large sample of

254 species. More generally, female preferences for certain males occur in virtually every

255 species in which researchers have looked for it (Keddy-Hector 1992; Clutton-Brock and

256 McAuliffe 2009). It is difficult to compare the relative influence of female preferences

257 on the distribution of matings across species because this distribution may also be

258 influenced by other factors. For instance, mating skew can be a consequence of both

259 female preference as well as male coercion and male-male competition which can both

260 constrain female choice (Clutton-Brock and McAuliffe 2009). Furthermore, female

261 preferences can vary between species such that mating skew may be high in one species 
262 because all females prefer the alpha male but low in other species because females

263 prefer to mate with many males. Other measures such as paternity concentration

264 introduce yet more confounding effects like cryptic female choice or sperm competition.

265 Hence, no clear behavioral measure that captures the actually expressed degree of

266 female choice is available across species.

267 One thing however is certain: where there is only one male, there is little or no

268 opportunity for female choice. As obvious as it may sound, this can have serious

269 consequences for male-female relationships: For instance, in species where both one-

270 male and multi-male groups occur, female choice is expressed only in multi-male

271 groups (Launhardt et al. 2001), and only males in multi-male groups engage in consorts

272 (Hamilton and Bulger 1992). In species that live in one-male units but form modular

273 societies, which are effectively like multi-male groups because other males are

274 constantly present and threaten to lure away or take over females, male-female

275 grooming rates within units are significantly higher than in non-modular species

276 (Grueter 2009). In fact, affiliative male-female relationships have never been reported in

277 single-male, multi-female groups but are common in multi-male, multi-female groups

278 (Tomasello and Call 1997; Silk 2002). Hence we use the occurrence of multi-male

279 groups in a species (yes/no) as a proxy for the opportunity for female choice (Source:

280 Rowe 1996), because the only clear "0's" for female choice are one-male groups. If

281 different types of social organization occur in a species, the multi-male score was given.

282 It is important to point out that the presence of multiple males does not simply lead to

283 more opportunities for sharing, because male-female proximity is generally lower in

284 multi-male groups (e.g. baboons vs. langurs), otherwise females would be 
285 monopolizable by a single male and it would not be a multi-male group (van Schaik and van Hooff 1983). Hence a positive result is not a byproduct of male-female proximity. In addition, we used a bibliographic frequency measure to validate our use of this binary variable and to predict the actually expressed frequency of male-female sharing and female mate choice within multi-male species. To this end, we searched the ISI Web of Science (all years) for the name of species X (e.g. "Pan troglodytes"), and also for the name of species X and the term "female mate choice" (e.g. "Pan troglodytes female mate choice"). We then divided the number of male-female food sharing studies on species $\mathrm{X}$ from Table 1 by the number of hits for the search on that species (we'll call this variable bibliographic frequency of male-female food sharing) and the number of hits on species X and "female mate choice" by the total number of hits on species X (bibliographic frequency of female mate choice). mating effort in pair-bonded species (e.g. Fragaszy and Mason 1983; Wolovich et al. 2006; Wolovich et al. 2008a; Wolovich et al. 2008b). Because pair bonds mainly occur

300 in single-male species, we tested this hypothesis by comparing male-female sharing in socially monogamous vs. harem (single-male, multi-female) species (Source: Rowe 1996). If other types of social organization (e.g. polyandry) also occur in a species, the monogamy score was given.

\section{Sharing among males / among females - Coalitions ("Food for support")}

In species in which individuals may form coalitions during agonistic

306 interactions, potential recipients have leverage over possessors because they may

307 provide or withhold coalitionary support in the future. As with female mate choice, it is 308 the possibility of partner choice in coalition formation, and hence the risk of losing a 
309 valuable partner, that should make possessors comply with recipients' request. Thus we

310 predict that the occurrence of sharing is associated with the occurrence of coalitions

311 (yes/no) across species. In particular, sharing among males should be associated with

312 male-male coalitions and sharing among females with female-female coalitions (Source:

313 Plavcan et al. 1995). In order to control for the possibility that both sharing and

314 coalition formation independently evolved by kin selection alone, we also restricted the

315 dataset to non-kin, i.e. we scored all species as " 0 " in which the only reported instances

316 of sharing occurred among relatives, as indicated by the authors of the respective studies

317 (Table 1).

318 Future analyses could also incorporate more detailed variables such as the

319 relative frequency of coalitions and their contribution to an individual's reproductive

320 success as well as same-sex grooming rates. We propose that the presence or absence of

321 coalitions is an appropriate predictor for the presence or absence of social bonds which

322 are translated into the presence or absence of sharing per se, whereas the more detailed

323 measures above could be used to quantify the relative strength of these bonds and thus

324 predict the frequency of sharing.

325 Comparative analyses

326 We used both maximum likelihood and Bayesian approaches to test for

327 correlated evolution of the traits of interest while controlling for phylogenetic non-

328 independence. The phylogeny of primates including branch lengths was based on

329 Bininda-Emonds et al. (2007, see Figure 1). First, we fitted phylogenetic regression

330 models using generalized estimating equations (GEE) for discrete traits and

331 phylogenetic generalized least squares (PGLS) for continuous variables (Paradis 2006).

332 All models were fitted with the ape package (Paradis et al. 2009) in R 2.12.1 (R 
333 Development Core Team 2010), with binomial (for binary traits) or poisson (for 0/1/2) error distributions for GEE, and Brownian correlation structure for PGLS. Markov chain Monte Carlo (RJ MCMC, Pagel and Meade 2006). RJ MCMCs are used to model the evolution of two binary traits assuming either dependent or independent evolution (the latter being the null hypothesis). Similar to a likelihood-ratio test, the dependent and independent models are compared by their harmonic means, the Bayesian equivalent of the log-likelihood, by calculating the log Bayes factor (BF).

341 Rather than testing the BF against a distribution such as chi square, by convention, a BF

$342>2$ is taken as positive evidence for dependent evolution, $\mathrm{BF}>5$ as strong positive

343 evidence and BF >10 as very strong positive evidence (Pagel and Meade 2006).

344 Furthermore, even in the dependent models, the chain can visit models with independent 345 evolution. Thus, if the proportion of independent models visited, $\mathrm{P}_{\text {independent, }}$, is small, the 346 null hypothesis of independent evolution of the two traits can also be rejected. In addition, RJ MCMC can be used to indicate the likelihood of trait changes, so-called "rate parameters", $q$ (Pagel and Meade 2006). If two traits can have the states

3490,0 (both absent), 0,1 (first trait absent, second trait present), 1,0 (first trait present, second trait absent) or 1,1 (both traits present), the rate parameters $q$ indicate the likelihood of transition between these states (cf. Figure 3). Hence, one can test whether

352 the evolution of one trait, e.g. "sharing among adults", is more likely in the presence or 353 the absence of the other trait, e.g. "sharing with offspring", by comparing the $q$ for the 354 transition from 0,1 to 1,1 with the $q$ for the transition from 0,0 to 1,0 . For a first examination of this, one can plot the posterior distribution of rate parameters simulated 
357 the likely evolutionary routes of state transitions by modifying the thickness of the

358

359

360

361

362

363

364

365

366

367

368

369

370

371

372

373

374

375

376

377

378

379

380

arrows according to the mean rate parameters (cf. Figure 3). In all models, the ancestral state for every trait was estimated to be 0 or 1 with almost equal probability (range of probability for $0=0.49-0.53$ ). However, given that relinquishing food to another individual's benefit as well as providing coalitionary support is costly and thus more unexpected than not doing so, and given that ancestral primates were most probably solitary and nocturnal and all other social systems derived (van Schaik and van Hooff 1983), we propose that ancestral states were probably 0,0 .

RJ MCMC models were run in BayesTraits 1.0 (Pagel and Meade) with a burnin of 50,000 and 5,050,000 iterations in total, except for male-female sharing, for which 10,050,000 iterations were run because the Markov chains tended to converge later. The first $1,000,000$ iterations $(2,000,000$ for male-female $)$ were discarded. We used an exponential hyperprior (Pagel et al. 2004) because of the relatively weak signal in the data (compared to, e.g. genetic data) and because small values of parameters were more likely than larger ones (i.e. the traits of interest evolved only relatively rarely), and made sure the posterior distribution of parameters was not truncated by the range of the parameter (see Online Resource 1). We used three different Rate Deviation settings and each model was run six times for each setting to verify that the results were stable (see Online Resource 2). The reported $\mathrm{BF}$ and $\mathrm{P}_{\text {independent }}$ are based on means of the six runs for the Rate Deviation setting that produced the best converging chains and recommended acceptance (see Online Resource 2). Furthermore, for each analysis we plotted the Markov chains and histograms of harmonic means for the reported dependent and independent models to show that the chains did indeed converge to a stable level and the difference between dependent and independent models was constant 
381 (Online Resource 3). Finally, we ran each analysis once using a much higher number of

382 iterations $(20,050,000)$ to ensure that the chains did not deviate again from the converged level (Figure available on request).

385 Results

386 General patterns

Of the 68 species in the sample, 38 (55.9\%) were reported to share food with offspring. In no species was food shared among adults but not with offspring. Of those 38 species in which food was shared with offspring, in 17 (44.7\%) food was also shared among adults. In particular, in 14 species males shared with females, and in seven species each males and females shared among themselves. This distribution of sharing among adults in relation to the presence of sharing with offspring and other predictor variables is summarized in Table 2. Fisher's exact probabilities indicate that these variables are significantly associated. Restricting sharing to non-kin improved the association with coalition formation for males and females. This overview lends preliminary support to the hypothesis that sharing among adults is related to opportunities for partner choice.

Sharing with offspring

Sharing with offspring was significantly positively predicted by the degree of

400 extractive foraging $\left(\mathrm{GEE}: \mathrm{F}_{1,65}=7.23, \mathrm{P}<0.05\right)$ but not by diet quality index $\left(\mathrm{F}_{1,65}=0.25\right.$,

$401 \mathrm{P}=0.62)$ and the interaction term was a significant negative predictor $\left(\mathrm{F}_{1,65}=6.12\right.$,

$402 \mathrm{P}<0.05$, see Table 3 for parameter estimates). This indicates that the difficulty of acquisition, rather than the nutritional quality of food predicts sharing with offspring 
404 and that difficult high quality diets do not lead to more sharing than difficult low quality

405 items.

406 Sharing among adults (any sex combination)

407 Species sharing among adults represented a strict subset of those species sharing

408 with offspring (Figure 1, Table 2). Thus, sharing with offspring strongly predicted

409 sharing among adults (GEE: $\left.\mathrm{F}_{1,65}=21.75, \mathrm{P}<0.001\right)$ whereas the two diet variables did

410 not (Extractive foraging: $\mathrm{F}_{1,65}=2.42, \mathrm{P}=0.15 ; D Q I: \mathrm{F}_{1,65}=0.95, \mathrm{P}=0.35$; see Table 3 for

411 parameter estimates). The RJ MCMC provided very strong support for dependent

412 evolution of these two traits: the log Bayes factor, comparing the harmonic means of the

413 dependent and the independent model, was very high and the chain never (!) visited

414 independent evolution (see Table 3). The posterior distribution of rate parameters (given

415 in Online Resource 1 and summarized in Figure 3a) also strongly indicated dependent

416 evolution (compare e.g. $q_{13}$ vs. $q_{24}$ for probability of evolutionary gain of the trait

417 "sharing among adults" in absence or presence of the trait "sharing with offspring").

418 Because sharing with offspring can thus be seen as a necessary precondition for

419 or a constraint on the evolution of sharing among adults, we reduced our sample to

420 species already sharing with offspring $(\mathrm{N}=38)$ in order to further test what factors

421 explain sharing among specific sex combinations of adults. The two diet variables did

422 not predict sharing among adults in general and were also never significant if included

423 in the subsequent models, thus the details of these analyses are not reported.

426 Sharing among adults (specific sex combinations)

427 From males to females 
The presence of multi-male groups significantly predicted sharing from males to females $\left(\mathrm{F}_{1,37}=6.53, \mathrm{P}<0.05\right.$, see Table 3$)$ and the RJ MCMC also provided positive evidence for dependent evolution of these two traits (Table 3, Online Resource 1). Within single-male species $(\mathrm{N}=15)$ male-female sharing only occurs in socially monogamous and never in single-male multi-female species (means: $0.20 \mathrm{vs.} 0$; because of the strong association, GEE could not be computed). Hence the female mate choice hypothesis for the evolution of sharing from males to females was supported (Figure 2a) whereas the pair-bonds hypothesis may be supported within single-male species. significantly higher in multi-male species than in single-male species (Wilcoxon: $\mathrm{W}=432, \mathrm{P}<0.01$, Online Resource 4), indicating that females in multi-male groups do indeed have more opportunities for mate choice which validates our use of this binary variable to measure female choice. Finally, within multi-male species $(\mathrm{N}=23)$, the bibliographic frequency of female mate choice significantly predicts the bibliographic

442 frequency of male-female food sharing (PGLS: Intercept $( \pm \mathrm{SE})=0.001( \pm 0.003)$,

$443 \mathrm{t}=0.37, \mathrm{P}=0.72 ;$ female mate choice $=0.22( \pm 0.09), \mathrm{t}=2.35, \mathrm{P}<0.05$, Online Resource 4$)$,

444 suggesting that male-female sharing is more frequent in multi-male species with more 445 female choice.

\section{$\underline{\text { Among males }}$}

The presence of male-male coalitions significantly predicted male-male sharing (GEE: $\mathrm{F}_{1,37}=6.15, \mathrm{P}<0.05$, Table 3, Figure $2 \mathrm{~b}$ ) and the RJ MCMC also provided strong

449 support for dependent evolution (Table 3, Figure 3b, Online Resource 1). Hence, the 450 hypothesis that male-male sharing co-evolved with male-male coalitions was supported. 
To further exclude the influence of kinship, species for which sharing has only been reported among (confirmed or suspected) relatives were given a " 0 ". Specifically, this concerned Saguinus fuscicollis and Pithecia pithecia, both of which do not form male-male coalitions (Table 1). Because there was an even stronger association between sharing (1) and coalition formation (1) and not sharing (0) and no coalition formation (0) respectively in the resulting sample (cf. Table 2), GEE's could not be computed. However, as expected from this stronger association, the RJ MCMC provided even stronger support for correlated evolution of sharing among unrelated males and malemale coalitions (Table 3, Figure 3b, Online Resource 1). Thus, the hypothesis that malemale sharing co-evolved with male-male coalitions was supported even better when only sharing among unrelated males was considered.

$\underline{\text { Among females }}$

The presence of female-female coalitions significantly predicted sharing (GEE: hypothesis that female-female sharing co-evolved with female-female coalitions was supported.

To further exclude the influence of kin selection, species for which sharing has only been reported among (confirmed or suspected) relatives were given a " 0 ".

470 Specifically, this concerned Nomascus concolor, Pongo abelii and Pongo pygmaeus. No

471 relatedness information could be obtained for the group of Pygathrix nemaeus studied

472 by Kavanagh (1972), hence non-kin food sharing was treated as unknown. None of 473 these species form female-female coalitions (Table 1). Again, because there was an even stronger association between sharing (1) and coalition formation (1) and not 
475 sharing (0) and no coalition formation (0) respectively in the resulting dataset (cf. Table 476 2), GEE's could not be computed. However, as expected from this stronger association, 477 the RJ MCMC provided even stronger support for correlated evolution of sharing 478 among unrelated females and female-female coalitions (Table 3, Figure 3b, Online 479 Resource 1). Thus, the hypothesis that female-female sharing co-evolved with female480 female coalitions was supported even better when only sharing among unrelated 481 females was considered. (insert Figure 3 about here)

\section{Discussion}

In this study, we tested several hypotheses about the evolution of food sharing in primates. Firstly, sharing with offspring was predicted by the degree of extractive foraging, which should indicate the relative processing difficulty of food items and thus the relative benefits to offspring gained from food transfers. Secondly, sharing with offspring in return strongly predicted sharing among adults to the extent that the latter could only evolve in presence of the former (see Figure 3a). Diet variables on the other hand did not predict sharing among adults. Thirdly, food sharing among (unrelated) adults coevolved with conditions for partner choice and thus the opportunity for reciprocal exchange (see Figure 3b). In particular, our analyses suggest that males share with females whenever these can bias matings to other males, i.e. when there is opportunity for female mate choice ("food for sex"), and males and females share in species that form coalitions ("food for support"). By excluding sharing among relatives,

496 we could rule out kin selection as a primary evolutionary mechanism. Thus, reciprocal exchange seems to be a main explanation accounting for the presence of sharing among unrelated adults across a large sample of primates. These overall findings are 
499 summarized in Figure 4. In addition, there was some indication that within single-male

500 species, male-female sharing was more common in socially monogamous species. The

501 current analyses could in the future be extended with more detailed behavioral variables

502 such as sex-combination specific grooming rates, the frequency of coalitions and their

503 influence on reproductive success, the actual amount of exerted female mate choice

504 (e.g. the percentage of female-initiated matings), etc. and predict frequencies rather than 505 just presence of sex-combination specific sharing.

(insert Figure 4 about here)

The result that sharing coevolved with opportunities for partner choice across a

508 broad range of species is in line with more detailed, within-species analyses testing for

509 the exchange of food with itself and various other services between individuals of the

510 same population (e.g. de Waal 1989; de Waal 1997; de Waal 2000; Gilby 2006; Mitani

511 2006; Gomes and Boesch 2009; Jaeggi et al. 2010c). As laid out in the introduction, the

512 fact that sharing is most often elicited by harassment does not speak against the

513 occurrence of reciprocal exchange in a statistically measurable way that can be under

514 selection. This study thus lends further support to the growing body of evidence for the

515 reciprocal exchange of low-cost altruistic acts among primates (Silk 2002; Schino 2007;

516 Schino and Aureli 2009).

517 Sharing among adults only evolved in a subset of species, namely those in which

518 sharing with offspring had already been established, indicating that the preexistence of

519 sharing with offspring may constrain the evolution of sharing among adults (Figure 3a).

520 The latter can therefore be seen as derived behavior (Tinbergen 1952), which could be

521 pressed into service in another context. An analogous example would be courtship

522 feeding in birds (Amat 2000), which is clearly derived from offspring provisioning, 
523 employing the same behavioral patterns (Lorenz 1965). Interestingly, courtship feeding 524 is also used among juvenile birds to strengthen social bonds (von Bayern et al. 2007) or establish dominance relationships (Scheid et al. 2008). However, the bird studies also show a clear functional difference between possessor-initiated sharing, which is derived

527 from provisioning and actively used as a costly signal, and recipient-initiated sharing,

528 which is a passive response to a request by an important social partner and may thus 529 lead to reciprocal exchange (Scheid et al. 2008). Only the latter form is common among 530 adult primates (Jaeggi et al. 2010a).

531 Diet did not seem to predict or constrain sharing among adults as the diet

532 variables included in the analysis never improved the models or reached significance. It 533 may well be that the diet variables were too broad to capture any variation in the occurrence of feeding situations with cost/benefit-ratios conducive to food transfers that may exist between species (Kaplan and Hill 1985). On the other hand, while certain food types such as meat and large fruit in the diet will surely lead to more frequent

537 sharing, the fact that sharing also occurs with trivial food items (Kavanagh 1972;

538 Slocombe and Newton-Fisher 2005; van Noordwijk and van Schaik 2009) indicates that 539 diet alone cannot explain the presence of sharing per se.

Although the associations we found between food sharing and the predictor

541 variables were significant, they were not absolute. Thus, some species in which sharing

542 could potentially have been used to maintain coalitionary relationships or facilitate mate 543 choice did not do so (cf. Table 2). For instance, no sharing occurs among olive baboon 544 males despite the presence of male-male coalitions (Table 1). This can be explained by 545 the steep dominance hierarchy in this species, allowing dominant males to acquire food 546 by force and not having to depend on (and thus share with) other males for coalitionary 
547 support. Coalitions are only formed by post-prime males who do not get a chance to

548 become food possessors and thus cannot trade food for support (Strum 1975; Strum

549 1981; Noë and Sluijter 1995). Similar arguments can be made for dominance constraints

550 on food for support among females or female mate choice. Hence strong dominance

551 hierarchies can obviate opportunities for reciprocal exchange (Trivers 1971; Noë and

552 Hammerstein 1995; Jaeggi et al. 2010c).

553 Given shareable items and the conditions shown here to be associated with

554 sharing, our results allow predictions that tested with more detailed analyses. For

555 instance, the causal link between multi-male groups and male-female sharing could be

556 investigated by comparing single-male vs. multi-male groups of the same species

557 (Hamilton and Bulger 1992; Launhardt et al. 2001) or by comparing closely related

558 modular and non-modular species (Yeager and Kirkpatrick 1998; Grueter and van

559 Schaik 2009). In particular, among Asian colobines tolerance within one-male units is

560 higher in modular species (Grueter 2009) and some sharing has been reported in

561 captivity (Kavanagh 1972; Zhang et al. 2008). Furthermore, species with high levels of

562 cooperation among males, such as Ateles geoffroyi (Aureli et al. 2006) or Cacajao

563 calvus (Bowler and Bodmer 2009), should have evolved strong bonds potentially

564 expressed in sharing. If sharing is rare or absent in the wild, simple experiments using

565 monopolizable food in captivity (e.g. de Waal 1989; de Waal 1997; Zhang et al. 2008;

566 Jaeggi et al. 2010c) could be used to test these predictions.

567 Furthermore, any other animal species in which opportunities for partner choice

568 and thus social bonds occur should potentially share food. However, diet type may turn

569 out to be a stronger constraint on sharing than in primates, where virtually every species

570 consumes some items prone to be shared (Harding 1981). For instance, dolphins and 
571 other toothed whales form alliances and have long-lasting social relationships (Connor et al. 1998; Connor 2007) but there are only a few reports of food sharing (Johnson 1982; Hoelzel 1991; Guinet et al. 2000), probably because the majority of consumed items (fish) are too small to be shared and because of observation difficulties. Similarly, elephants (Poole and Moss 2008) and many birds (Emery et al. 2007) have complex social relationships but may not encounter food items likely to be shared. Nonetheless, these species could easily be tested in captivity. On the other hand, very large food items such as animal carcasses containing many times the quantity an individual could consume alone make sharing almost inevitable because the benefits of defending are minimal to the point of monopolization becoming impractical. Thus, carcass sharing occurs in ravens (Heinrich 1988a; Heinrich 1988b) and many social carnivores (e.g. East and Hofer 1991) but may not represent sharing as defined here and is thus not necessarily linked to exchange of other favors. Furthermore, some instances of non-kin sharing among animals clearly serve other functions such as mate provisioning (Vahed 1998) or costly signaling (Zahavi 1990; Scheid et al. 2008). Lastly, food sharing is also a universal feature of human forager societies and most of the functional hypotheses discussed here probably apply to some extent (Kaplan and Hill 1985; Hawkes 1993; Gurven 2004; Marlowe 2004; Gurven and Hill 2009). However, it should be noted that rather than being a relatively infrequent event as in

590 primates, human food sharing takes the form of daily provisioning both within and

591 between families and is an indispensable component of the human foraging niche and

592 cooperative breeding system (Kaplan and Gurven 2005; Hrdy 2009; Kaplan et al. 2009).

593 Thus, sharing has a higher adaptive value than in other species which has probably led 594 to a more active and prosocial sharing psychology in humans (Jaeggi et al. 2010a). 
595

596

597

598

599

600

601

602

603

604

605

606

607

608

609

610

611

612

613

614

615

616

617

\section{Acknowledgements}

The authors would like to thank Michael Gurven, Karin Isler, Charles Nunn,

Gabrielle Russo, Maria van Noordwijk, Janneke van Woerden, the UCSB's Human

Behavioral Ecology Lab and several anonymous reviewers for discussions and many

helpful comments on earlier versions of the manuscript. We also thank Charles Nunn for sharing parts of his forthcoming book "The comparative method in evolutionary anthropology and biology" which was highly informative for the methods used in this study. Finally, we are very grateful to the Swiss National Science Foundation (grant PBZHP3-133433), the Cogito Foundation (grant S-106/06) and the A.H. Schultz Foundation for financial support to AJ. The authors declare no conflict of interest.

\section{References}

Amat JA (2000) Courtship feeding, food sharing, or tolerated food theft among paired red-crested pochards (Netta rufina)? Journal für Ornithologie 141:327-334

Aureli F, Schaffner CM, Verpooten J, Slater K, Ramos-Fernandez G (2006) Raiding parties of male spider monkeys: Insights into human warfare? American Journal of Physical Anthropology 131:486-497

Bininda-Emonds ORP, Cardillo M, Jones KE, MacPhee RDE, Beck RMD, Grenyer R, Price SA, Vos RA, Gittleman JL, Purvis A (2007) The delayed rise of presentday mammals. Nature 446:507-512

Blurton Jones NG (1984) A selfish origin for human food sharing: Tolerated theft. Ethology and Sociobiology 5:1-3

Blurton Jones NG (1987) Tolerated theft: Suggestions about the ecology and evolution of sharing, hoarding, and scrounging. Social Science Information 26:31-54 
618 Bowler M, Bodmer M (2009) Social behavior in fission-fusion groups of red uakari 619 monkeys (Cacajao calvus ucayalii). American Journal of Primatology 71:976$620 \quad 987$

621 Brown GR, Almond REA, Van Bergen Y (2004) Begging, stealing, and offering: Food 622 transfer in nonhuman primates. Advances in the Study of Behavior 34:265-295

623 Cashdan EA (1997) Comment on Bliege Bird and Bird: Delayed reciprocity and 624 tolerated theft. Current Anthropology 38:69-70

625 Clutton-Brock T, McAuliffe K (2009) Female mate choice in mammals. Quarterly 626 Review of Biology 84:3-27

627 Clutton-Brock TH (1991) The evolution of parental care. Princeton Univ Press, 628 Princeton, NJ

629

Clutton-Brock TH (2009) Cooperation between non-kin in animal societies. Nature

630 $462: 51-57$

631 Connor RC (2007) Dolphin social intelligence: complex alliance relationships in bottlenose dolphins and a consideration of selective environments for extreme brain size evolution in mammals. Philosophical Transactions of the Royal Society B: Biological Sciences 362:587-602

Connor RC, Mann J, Tyack PL, Whitehead H (1998) Social evolution in toothed

637 Cords M (1997) Friendships, alliances, reciprocity and repair. In: Whiten A, Byrne RW (eds) Machiavellian intelligence II: Extensions and evaluations. Cambridge Univ

640 de Waal FBM (1989) Food sharing and reciprocal obligations among chimpanzees. 641 Journal of Human Evolution 18:433-459 
642 de Waal FBM (1997) The chimpanzee's service economy: Food for grooming.

643 Evolution and Human Behavior 18:375-386

644 de Waal FBM (2000) Attitudinal reciprocity in food sharing among brown capuchin

645 monkeys. Animal Behaviour 60:253-261

646 East ML, Hofer H (1991) Loud calling in a female-dominated mammalian society: II.

647 Behavioural contexts and functions of whooping of spotted hyaenas, Crocuta

$648 \quad$ crocuta. Animal Behaviour 42:651-669

649 Emery NJ, Seed AM, von Bayern AMP, Clayton NS (2007) Cognitive adaptations of

650 social bonding in birds. Philosophical Transactions of the Royal Society B-

$651 \quad$ Biological Sciences 362:489-505

652 Feistner ATC, McGrew WC (1989) Food-sharing in primates: A critical review. In:

653 Seth PK, Seth S (eds) Perspectives in primate biology. Volume 3. Today and

654 Tomorrow's Printers and Publishers, New Delhi, India, pp 21-36

655 Fish JL, Lockwood CA (2003) Dietary constraints on encephalization in primates.

656 American Journal of Physical Anthropology 120:171-181

657 Forss SIF, van Noordwijk MA, Jaeggi AV, Meulman EM, van Schaik CP (2009) Social

658 construction of the feeding niche in orang-utans: a comparative study. Folia

$659 \quad$ Primatologica 80:117-118

660 Fragaszy DM, Mason WA (1983) Comparisons of feeding behavior in captive squirrel

661 and titi monkeys (Saimiri sciureus and Callicebus moloch). Journal of

$662 \quad$ Comparative Psychology 97:310-326

663 Gibson KR (1986) Cognition, brain size and the extraction of embedded food resources.

664 In: Else J, Lee PC (eds) Primate ontogeny, cognition and social behaviour.

665 Cambridge University Press, Cambridge 
666 Gilby IC (2006) Meat sharing among the Gombe chimpanzees: harassment and 667 reciprocal exchange. Animal Behaviour 71:953-963

668

Gilby IC, Emery Thompson M, Ruane JD, Wrangham RW (2010) No evidence of short669 term exchange of meat for sex among chimpanzees. Journal of Human Evolution

670 $59: 44-53$

671

Gomes CM, Boesch C (2009) Wild chimpanzees exchange meat for sex on a long-term 672 basis. PLoS ONE 4:e5116

673

Gomes CM, Mundry R, Boesch C (2009) Long-term reciprocation of grooming in wild 674 675 West African chimpanzees. Proceedings of the Royal Society B-Biological

676

677 (Rhinopithecus bieti) and other Asian colobines. PhD thesis. In. University of Zurich, Zurich

679

Grueter CC, van Schaik CP (2009) Sexual size dimorphism in Asian colobines

680 revisited. American Journal of Primatology 71:609-616

Guinet C, Barrett-Lennard LG, Loyer B (2000) Co-ordinated attack behavior and prey 682 sharing by killer whales at Crozet archipelago: Strategies for feeding on 683 negatively-buoyant prey. Marine Mammal Science 16:829-834

Gurven M (2004) To give and to give not: The behavioral ecology of human food transfers. Behavioral and Brain Sciences 27:543-583

Gurven M, Hill K (2009) Why do men hunt? A reevaluation of "man the hunter" and 687 the sexual division of labor. Current Anthropology 50:51-74 Biology 7:1-16 
690 Hamilton WJ, Bulger J (1992) Facultative expression of behavioral differences between one-male and multimale savanna baboon groups. American Journal of

692 Primatology 28:61-71

Harding RSO (1981) An order of omnivores: Nonhuman primate diets in the wild. In: Harding RSO, Teleki G (eds) Omnivorous primates: Gathering and hunting in human evolution. Columbia University Press, New York, pp 191-214

Hawkes K (1993) Why hunter-gatherers work - an ancient version of the problem of public goods. Current Anthropology 34:341-361

Heinrich B (1988a) Food sharing in the raven, Corvus corax. In: Slobodchikoff CN (ed) The ecology of social behavior. Academic Press, San Diego, pp 285-311

Heinrich B (1988b) Winter foraging at carcasses by 3 sympatric corvids, with emphasis on recruitment by the raven, Corvus corax. Behavioral Ecology and Sociobiology 23:141-156

Hill K, Kaplan H (1993) On why male foragers hunt and share food. Current Anthropology 34:701-706

Hockings KJ, Humle T, Anderson JR, Biro D, Sousa C, Ohashi G, Matsuzawa T (2007) Chimpanzees share forbidden fruit. PLOS ONE 2:e886(online 1-4)

Hoelzel AR (1991) Killer whale predation on marine mammals at Punta Norte, Argentina - Food sharing, provisioning and foraging strategy. Behavioral Ecology and Sociobiology 29:197-204

710 Hohmann G, Fruth B (2008) New records on prey capture and meat eating by bonobos 
713 Hrdy S (2009) Mothers and others: The evolutionary origins of mutual understanding. Harvard University Press, Cambridge

715

716 species. Ballantine Books, New York

Jaeggi AV, Burkart JM, van Schaik CP (2010a) On the psychology of cooperation in humans and other primates: Combining the natural history and experimental evidence of prosociality. Philosophical Transactions of the Royal Society BBiological Sciences 365:2723-2735

Jaeggi AV, Dunkel LP, van Noordwijk MA, Wich SA, Sura AAL, van Schaik CP (2010b) Social learning of diet and foraging skills among wild immature Bornean orangutans (Pongo pygmaeus wurmbii): Implications for culture. American Journal of Primatology 72:62-71

Jaeggi AV, Stevens JMG, van Schaik CP (2010c) Tolerant food sharing and reciprocity is precluded by despotism in bonobos but not chimpanzees. American Journal of Physical Anthropology 143:41-51

Johnson RH (1982) Food-sharing behavior in captive Amazon river dolphins (Inia geoffrensis). Cetology 43:1-3

Kaplan H, Gurven M (2005) The natural history of human food sharing and cooperation: A review and a new multi-individual approach to the negotiation of norms. In: Gintis H, Bowles S, Boyd R, Fehr E (eds) Moral sentiments and material interests: The foundations of cooperation in economic life. MIT Press, Cambridge, pp 75-113

Kaplan H, Hill K (1985) Food sharing among Ache foragers: Tests of explanatory hypotheses. Current Anthropology 26:223-246 
737 Kaplan HS, Hooper PL, Gurven M (2009) The evolutionary and ecological roots of human social organization. Philosophical Transactions of the Royal Society BBiological Sciences 364:3289-3299

Kavanagh M (1972) Food-sharing behavior within a group of douc monkeys (Pygathrix nemaeus nemaeus). Nature 239:406-7

Kawanaka K (1982) Further studies on predation by chimpanzees of the Mahale Mountains. Primates 23:364-384

Keddy-Hector AC (1992) Mate choice in non-human primates. American Zoologist $32: 62-70$

Launhardt K, Borries C, Hardt C, Epplen JT, Winkler P (2001) Paternity analysis of alternative male reproductive routes among the langurs (Semnopithecus entellus) of Ramnagar. Animal Behaviour 61:53-64

Lorenz K (1965) Evolution and the modification of behavior. Chicago University Press, Chicago

Marlowe FW (2004) What explains Hadza food sharing? Research in Economic

753 Anthropology 23:69-88

Mas F, Kölliker M (2008) Maternal care and offspring begging in social insects: chemical signalling, hormonal regulation and evolution. Animal Behaviour $76: 1121-1131$

Massen JJM, Sterck EHM, de Vos H (2010) Close social associations in animals and humans: functions and mechanisms of friendship. Behaviour 147:1379-1412

Mitani JC (2006) Reciprocal exchange in chimpanzees and other primates. In: Kappeler PM, van Schaik CP (eds) Cooperation in primates and humans: mechanisms and evolution. Springer, New York, pp 107-119 
761 Mitani JC, Watts DP (2001) Why do chimpanzees hunt and share meat? Animal 762 Behaviour 61:915-924

Nettelbeck AR (1998) Observations on food sharing in wild lar gibbons (Hylobates lar). Folia Primatologica 69:386-391

Nishida T, Hasegawa T, Hayaki H, Takahata Y, Uehara S (1992) Meat-sharing as a coalition strategy by an alpha male chimpanzee? In: Nishida T, McGrew WC, Marler P, Pickford M, De Waal FBM (eds) Topics in primatology. Volume 1: Human origins. University of Tokyo Press, Tokyo, pp 159-174

Noë R, Hammerstein P (1995) Biological markets. Trends in Ecology \& Evolution 10:336-339

Noë R, Sluijter A (1995) Which adult male savanna baboons form coalitions? International Journal of Primatology 16:77-105

Pagel M, Meade A BayesTraits. In, 1.0 edn. Reading Evolutionary Biology Group, $\underline{\text { www.evolution.rdg.ac.uk }}$

Pagel M, Meade A (2006) Bayesian analysis of correlated evolution of discrete characters by reversible-jump Markov chain Monte Carlo. American Naturalist $167: 808-825$

Pagel M, Meade A, Barker D (2004) Bayesian estimation of ancestral character states on phylogenies. Systematic Biology 53:673-684

Paradis E (2006) Analysis of phylogenetics and evolution with R. Springer, New York

Paradis E, Bolker BM, Claude J, Cuong HS, Desper R, Durand B, Dutheil J, Gascuel O, Jobb G, Heibl C, Lawson D, Lefort V, Legendre P, Lemon J, Noel Y, Nylander J, Opgen-Rhein R, Strimmer K, de Vienne D (2009) Analyses of phylogenetics and evolution. In: 
785 Perry S, Rose L (1994) Begging and transfer of coati meat by white-faced capuchin monkeys, Cebus capucinus. Primates 35:409-415

787 Plavcan JM, van Schaik CP, Kappeler PM (1995) Competition, coalitions and canine size in primates. Journal of Human Evolution 28:245-276

Poole JH, Moss CJ (2008) Elephant sociality and complexity: The scientific evidence. In: Wemmer C, Christen K (eds) Elephants and Ethics: Towards a morality of coexistence. Johns Hopkins University Press, Baltimore

R Development Core Team (2010) R: A language and environment for statistical computing. In. R Foundation for Statistical Computing, Vienna, Austria

Rapaport LG, Brown GR (2008) Social influences on foraging behaviour in young nonhuman primates: Learning what, where and how to eat. Evolutionary Anthropology 17:189-201

797 Rowe N (1996) The pictorial guide to the living primates. Pogonias Press, Charlestown

Scheid C, Schmidt J, Noë R (2008) Distinct patterns of food offering and co-feeding in rooks. Animal Behaviour 76:1701-1707

800 Schessler T, Nash LT (1977) Food sharing among captive gibbons (Hylobates lar). 801 Primates 18:677-689

Schino G (2007) Grooming and agonistic support: a meta-analysis of primate reciprocal altruism. Behavioral Ecology 18:115-120

804 Schino G, Aureli F (2009) Reciprocal altruism in primates: Partner choice, cognition, and emotions. Advances in the Study of Behavior 39:45-69

806 Silk JB (2002) Using the'F'-word in primatology. Behaviour 139:421-446 
807 Slocombe KE, Newton-Fisher NE (2005) Fruit sharing between wild adult chimpanzees 808 (Pan troglodytes schweinfurthii): A socially significant event? American Journal of Primatology 65:385-391

Stanford CB (1999) The hunting apes: meat eating and the origins of human behavior. Princeton Univ Press, Princeton

Stevens JR (2004) The selfish nature of generosity: harassment and food sharing in primates. Proceedings of the Royal Society of London Series B-Biological Sciences 271:451-456

Stevens JR, Gilby IC (2004) A conceptual, framework for nonkin food sharing: timing

817 Stevens JR, Hauser MD (2004) Why be nice? Psychological constraints on the evolution of cooperation. Trends in Cognitive Sciences 8:60-65

Stevens JR, Stephens DW (2002) Food sharing: a model of manipulation by harassment. Behavioral Ecology 13:393-400

Strum SC (1975) Primate predation: Interim report on the development of a tradition in a troop of olive baboons. Science 187:755-757

Strum SC (1981) Processes and products of change: Baboon predatory behavior at Gathering and hunting in human evolution. Columbia University Press, New

827 Tinbergen N (1952) "Derived" activities; their causation, biological significance, origin, 828 and emancipation during evolution. The Quarterly Review of Biology 27:1-32 
830 Trivers RL (1971) Evolution of reciprocal altruism. Quarterly Review of Biology 46:35-

831

832

833

834

835

836

837

838

839

840

841

842

843

844

845

846

847

848

849

850

851

852

57

Utami SS, van Hooff JARAM (1997) Meat-eating by adult female Sumatran orangutans (Pongo pygmaeus abelii). American Journal of Primatology 43:159-165

Vahed K (1998) The function of nuptial feeding in insects: review of empirical studies. Biological Reviews 73:43-78

van Noordwijk MA, van Schaik CP (2009) Intersexual food transfer among orangutans: do females test males for coercive tendency? Behavioral Ecology and Sociobiology 63:883-890

van Schaik CP, Fox EA, Sitompul AF (1996) Manufacture and use of tools in wild Sumatran orangutans - Implications for human evolution. Naturwissenschaften $83: 186-188$

van Schaik CP, van Hooff JARAM (1983) On the ultimate causes of primate social systems. Behaviour 85:91-117

von Bayern AMP, de Kort SR, Clayton NS, Emery NJ (2007) The role of food- and object-sharing in the development of social bonds in juvenile jackdaws (Corvus monedula). Behaviour 144:711-733

Watts DP (2002) Reciprocity and interchange in the social relationships of wild male chimpanzees. Behaviour 139:343-370

White F (1994) Food sharing in wild pygmy chimpanzees (Pan paniscus). In: Roeder JJ, Thierry B, Anderson JR, Herrenschmidt N (eds) Current Primatology Volume II: Social development, learning and behavior, vol 2. Université Louis Pasteur, Strasbourg, pp 1-10 
853 Wolovich CK, Evans S, French JA (2008a) Dads do not pay for sex but do buy the milk: food sharing and reproduction in owl monkeys (Aotus spp.). Animal Behaviour 75:1155-1163

Wolovich CK, Feged A, Evans S, Green SM (2006) Social patterns of food sharing in monogamous owl monkeys. American Journal of Primatology 68:663-674

Wolovich CK, Perea-Rodriguez JP, Fernandez-Duque E (2008b) Food transfers to

859 young and mates in wild owl monkeys (Aotus azarai). American Journal of 860 Primatology 70:211-221

861

862

Ydenberg RC (1994) The behavioral ecology of provisioning in birds. Ecoscience 1:114

863 Yeager C, Kirkpatrick R (1998) Asian colobine social structure: Ecological and evolutionary constraints. Primates 39:147-155

Zahavi A (1990) Arabian babblers: the quest for social status in a cooperative breeder. In: Stacey PB, Koenig WD (eds) Cooperative breeding in birds: Long-term studies of ecology and behavior. Cambridge University Press, Cambridge, pp 103-130

Zhang Z, Su YJ, Chan RCK, Reimann G (2008) A preliminary study of food transfer in 870 Sichuan snub-nosed monkeys (Rhinopithecus roxellana). American Journal of Primatology 70:148-152 
TABLE 1: List of all the species included in the comparative analyses and the variables of interest

\begin{tabular}{|c|c|c|c|c|c|c|c|c|c|c|c|c|}
\hline Species $^{\mathrm{a}}$ & $\begin{array}{l}\text { FS } \\
\text { off. }\end{array}$ & $\begin{array}{l}\text { FS } \\
\text { ad. }\end{array}$ & $\begin{array}{l}\text { FS } \\
\hat{\sigma}-q\end{array}$ & $\begin{array}{l}\text { FS } \\
\hat{๐}-\widehat{~}\end{array}$ & $\begin{array}{c}\text { FS } \\
\circ-\uparrow\end{array}$ & $\begin{array}{l}\text { Extr. } \\
\text { For. }\end{array}$ & DQI & $\begin{array}{c}\text { Multi- } \\
\text { male }\end{array}$ & Monog. & $\begin{array}{l}\hat{\sigma}-\widehat{\jmath} \\
\text { coal. }\end{array}$ & $\begin{array}{c}q-q \\
\text { coal. }\end{array}$ & Ref. $^{b}$ \\
\hline Alouatta palliata & 1 & 0 & 0 & 0 & 0 & 0 & 0.43 & 1 & 0 & 0 & 0 & $1-4$ \\
\hline Aotus azarae & 2 & 2 & 1 & 0 & 0 & 0 & 0.65 & 0 & 1 & 0 & 0 & $5-7$ \\
\hline Ateles geoffreyoi & 1 & 0 & 0 & 0 & 0 & 0 & 0.61 & 1 & 0 & 1 & 0 & $8-10$ \\
\hline Callicebus discolor & 1 & 1 & 1 & 0 & 0 & 0 & 0.59 & 0 & 1 & 0 & 0 & 11,12 \\
\hline Callicebus lugens & 1 & 0 & 0 & 0 & 0 & 0 & 0.65 & 0 & 1 & 0 & 0 & 13 \\
\hline Callimico goeldii & 2 & 0 & 0 & 0 & 0 & 0 & 0.67 & 0 & 1 & 0 & 0 & $14-17$ \\
\hline Callithrix argentata & 2 & 0 & 0 & 0 & 0 & 1 & 0.67 & 1 & 1 & 0 & 0 & $18-20$ \\
\hline Callithrix jacchus & 2 & 1 & 1 & 0 & 0 & 1 & 0.67 & 1 & 1 & 0 & 0 & $21-32$ \\
\hline Callithrix pygmaea & 2 & 0 & 0 & 0 & 0 & 0 & 0.67 & 0 & 1 & 0 & 0 & 33,34 \\
\hline Cebus albifrons & 1 & 1 & 1 & 1 & 0 & 1 & 0.67 & 1 & 0 & 1 & 0 & 35 \\
\hline Cebus apella & 1 & 1 & 1 & 1 & 1 & 2 & 0.87 & 1 & 0 & 1 & 1 & $36-43$ \\
\hline Cebus capucinus & 1 & 1 & 1 & 1 & 0 & 2 & 0.65 & 1 & 0 & 1 & 0 & $44-46$ \\
\hline Cebus olivaceus & 0 & 0 & 0 & 0 & 0 & 2 & 0.87 & 1 & 0 & 0 & 0 & \\
\hline
\end{tabular}




\begin{tabular}{|c|c|c|c|c|c|c|c|c|c|c|c|c|}
\hline Cercocebus atys & 0 & 0 & 0 & 0 & 0 & 0 & 0.67 & 1 & 0 & 0 & 0 & \\
\hline Cercocebus torquatus & 0 & 0 & 0 & 0 & 0 & 0 & 0.67 & 1 & 0 & 0 & 1 & \\
\hline Cercopithecus campbelli & 0 & 0 & 0 & 0 & 0 & 0 & 0.70 & 0 & 0 & 0 & 0 & \\
\hline Cercopithecus diana & 0 & 0 & 0 & 0 & 0 & 0 & 0.69 & 0 & 0 & 0 & 0 & \\
\hline Cercopithecus mitis & 0 & 0 & 0 & 0 & 0 & 0 & 0.68 & 0 & 0 & 0 & 0 & \\
\hline Chiropotes satanas & 0 & 0 & 0 & 0 & 0 & 0 & 0.67 & 1 & 0 & 0 & 0 & \\
\hline Chlorocebus aethiops & 0 & 0 & 0 & 0 & 0 & 0 & 0.69 & 1 & 0 & 0 & 1 & \\
\hline Colobus guereza & 0 & 0 & 0 & 0 & 0 & 0 & 0.40 & 1 & 0 & 0 & 0 & \\
\hline Daubentonia madagascarensis & 1 & 0 & 0 & 0 & 0 & 2 & 0.84 & 0 & 0 & 0 & 0 & $47-49$ \\
\hline Erythrocebus patas & 0 & 0 & 0 & 0 & 0 & 0 & 0.69 & 0 & 0 & 0 & 0 & \\
\hline Eulemur fulvus & 0 & 0 & 0 & 0 & 0 & 0 & 0.59 & 1 & 0 & 0 & 0 & \\
\hline Eulemur rufus & 0 & 0 & 0 & 0 & 0 & 0 & 0.59 & 1 & 0 & 0 & 0 & \\
\hline Galago senegalensis & 1 & 0 & 0 & 0 & 0 & 0 & 0.63 & 0 & 0 & 0 & 0 & 50,51 \\
\hline Gorilla beringei & 1 & 0 & 0 & 0 & 0 & 1 & 0.34 & 0 & 0 & 0 & 0 & 52 \\
\hline Gorilla gorilla & 1 & 0 & 0 & 0 & 0 & 1 & 0.38 & 0 & 0 & 0 & 0 & 53 \\
\hline Hylobates lar & 1 & 0 & 0 & 0 & 0 & 0 & 0.71 & 0 & 1 & 0 & 0 & $54-59$ \\
\hline
\end{tabular}


Indri indri

Lemur catta

Leontopithecus rosalia

Lophocebus albigena

Macaca arctoides

Macaca fascicularis

Macaca fuscata

Macaca mulatta

Macaca nemestrina

Macaca radiata

Macaca silenus

Macaca sylvanus

Mandrillus sphinx

Microcebus murinus

Nasalis larvatus

Nomascus concolor

\begin{tabular}{|c|c|c|c|c|c|c|c|c|c|c|c|}
\hline 0 & 0 & 0 & 0 & 0 & 0 & 0.55 & 0 & 1 & 0 & 0 & \\
\hline 0 & 0 & 0 & 0 & 0 & 0 & 0.59 & 1 & 0 & 0 & 0 & \\
\hline 2 & 1 & 1 & 0 & 0 & 1 & 0.67 & 1 & 1 & 0 & 0 & $60-70$ \\
\hline 0 & 0 & 0 & 0 & 0 & 0 & 0.69 & 1 & 0 & 0 & 1 & \\
\hline 1 & 0 & 0 & 0 & 0 & 1 & 0.68 & 1 & 0 & 0 & 0 & 71 \\
\hline 1 & 0 & 0 & 0 & 0 & 1 & 0.74 & 1 & 0 & 1 & 1 & 72,73 \\
\hline 1 & 0 & 0 & 0 & 0 & 1 & 0.68 & 1 & 0 & 0 & 1 & 74,75 \\
\hline 0 & 0 & 0 & 0 & 0 & 1 & 0.68 & 1 & 0 & 0 & 1 & \\
\hline 0 & 0 & 0 & 0 & 0 & 1 & 0.62 & 1 & 0 & 0 & 1 & \\
\hline 0 & 0 & 0 & 0 & 0 & 1 & 0.68 & 1 & 0 & 1 & 0 & \\
\hline 0 & 0 & 0 & 0 & 0 & 1 & 0.68 & 1 & 0 & 0 & 0 & \\
\hline 0 & 0 & 0 & 0 & 0 & 1 & 0.68 & 1 & 0 & 1 & 0 & \\
\hline 0 & 0 & 0 & 0 & 0 & 0 & 0.67 & 1 & 0 & 0 & 0 & \\
\hline 0 & 0 & 0 & 0 & 0 & 0 & 0.76 & 0 & 0 & 0 & 0 & \\
\hline 0 & 0 & 0 & 0 & 0 & 0 & 0.53 & 1 & 0 & 0 & 0 & \\
\hline 1 & 1 & 0 & 0 & $1^{\mathrm{c}}$ & 0 & 0.43 & 0 & 1 & 0 & 0 & 76 \\
\hline
\end{tabular}




\begin{tabular}{|c|c|c|c|c|c|c|c|c|c|c|c|c|}
\hline Nycticebus coucang & 1 & 0 & 0 & 0 & 0 & 0 & 0.79 & 0 & 1 & 0 & 0 & 77 \\
\hline Pan paniscus & 2 & 2 & 1 & 1 & 1 & 2 & 0.61 & 1 & 0 & 0 & 1 & $78-87$ \\
\hline Pan troglodytes & 2 & 2 & 1 & 1 & 1 & 2 & 0.61 & 1 & 0 & 1 & 1 & $88-136$ \\
\hline Papio anubis & 1 & 1 & 1 & 0 & 0 & 1 & 0.66 & 1 & 0 & 1 & 0 & $137-139$ \\
\hline Papio cynocephalus & 0 & 0 & 0 & 0 & 0 & 1 & 0.65 & 1 & 0 & 0 & 0 & \\
\hline Papio hamadryas & 0 & 0 & 0 & 0 & 0 & 1 & 0.66 & 1 & 0 & 0 & 0 & \\
\hline Papio ursinus & 0 & 0 & 0 & 0 & 0 & 1 & 0.63 & 1 & 0 & 0 & 0 & \\
\hline Piliocolobus badius & 1 & 0 & 0 & 0 & 0 & 0 & 0.40 & 1 & 0 & 1 & 0 & 140 \\
\hline Pithecia pithecia & 1 & 1 & 0 & $1^{c}$ & 0 & 0 & 0.67 & 0 & 0 & 0 & 0 & 141 \\
\hline Pongo abelii & 2 & 1 & 1 & 0 & $1^{\mathrm{c}}$ & 2 & 0.59 & 1 & 0 & 0 & 0 & $142-144$ \\
\hline Pongo pygmaeus & 2 & 1 & 1 & 0 & $1^{\mathrm{c}}$ & 2 & 0.59 & 1 & 0 & 0 & 0 & $145-149$ \\
\hline Presbytis thomasi & 0 & 0 & 0 & 0 & 0 & 0 & 0.55 & 0 & 0 & 0 & 0 & \\
\hline Propithecus verreauxi & 0 & 0 & 0 & 0 & 0 & 0 & 0.56 & 1 & 0 & 0 & 0 & \\
\hline Pygathrix nemaeus & 1 & 1 & 1 & 0 & $1^{\mathrm{d}}$ & 0 & 0.54 & 1 & 0 & 0 & 0 & 150 \\
\hline Saguinus fuscicollis & 2 & 1 & 0 & $1^{\mathrm{c}}$ & 0 & 0 & 0.67 & 1 & 1 & 0 & 0 & $151-153$ \\
\hline Saguinus mystax & 2 & 1 & 1 & 0 & 0 & 0 & 0.67 & 1 & 1 & 0 & 0 & 154,155 \\
\hline
\end{tabular}




\begin{tabular}{|c|c|c|c|c|c|c|c|c|c|c|c|c|}
\hline Saguinus nigricollis & 1 & 0 & 0 & 0 & 0 & 0 & 0.67 & 1 & 1 & 0 & 0 & 156 \\
\hline Saguinus oedipus & 2 & 0 & 0 & 0 & 0 & 0 & 0.67 & 1 & 1 & 0 & 0 & $157-168$ \\
\hline Saimiri sciureus & 0 & 0 & 0 & 0 & 0 & 1 & 0.94 & 1 & 0 & 0 & 1 & 169,170 \\
\hline Semnopithecus entellus & 1 & 0 & 0 & 0 & 0 & 0 & 0.42 & 1 & 0 & 0 & 0 & 171 \\
\hline Symphalangus syndactylus & 1 & 0 & 0 & 0 & 0 & 0 & 0.49 & 0 & 1 & 0 & 0 & 172 \\
\hline Tarsius spectrum & 1 & 0 & 0 & 0 & 0 & 0 & 1.00 & 0 & 1 & 0 & 0 & 173 \\
\hline Theropithecus gelada & 0 & 0 & 0 & 0 & 0 & 0 & 0.40 & 1 & 0 & 0 & 1 & \\
\hline
\end{tabular}

${ }^{\mathrm{a}}$ Species names follow Groves (2001) and Brandon-Jones et al. (2004)

${ }^{\mathrm{b}}$ Ref. $=$ References for food sharing information. The full citation information for this list can be obtained from the first author ${ }^{c}$ Food sharing only reported among (confirmed or suspected) relatives, as indicated by the respective authors. The species were consequently given a 0 in the non-kin only analyses

${ }^{\mathrm{d}}$ No information on relatedness could be obtained for the subjects of this study and the occurrence of non-kin food sharing was thus treated as unknown in the respective analyses

FS = Food sharing, with offspring (off.), among adults (ad.), from males to females $(\hat{\jmath}-\varnothing)$, among males ( $\hat{\jmath}-\hat{\jmath})$, and among females $\left(q_{-}+\right.$) respectively. Extr. For. $=$The degree of extractive foraging, DQI = Diet quality index, Multi-male = multi-male groups,

Monog. = Monogamy, $\widehat{\partial}-\widehat{\delta} / q-q$ coal. $=$ male-male and female-female coalitions respectively 
References: ${ }^{1-4}$ Carpenter (1934, 1965), Baldwin \& Baldwin (1973), Whitehead (1986); ${ }^{5-7}$ Wolovich et al. $(2006,2008 \mathrm{a}, \mathrm{b}) ;{ }^{8-10}$ Dare (1974), Watt (1994), Pastor-Nieto (2001); ${ }^{11,12}$ Fragaszy \& Mason (1983), Wright (1984); ${ }^{13}$ Starin $(1978) ;{ }^{14-17}$ Lorenz (1969, 1972), Feistner \& Price (1991), Jurke \& Price (1994); ${ }^{18-20}$ Carroll (1978), Omedes (1981), Feistner \& Price (1991); ${ }^{21-32}$ Epple (1967), Hearn \& Lunn (1975), Chalmers \& Lockehaydon (1984), Feistner \& Price (1991), Vitale \& Queyras (1997), Yamamoto \& Box (1997), Westlund et al. (2000), Caldwell \& Whiten (2003), Brown et al. (2005), de Lyra-Neves et al. (2007), Kasper et al. (2008), Saito et al. (2008); ${ }^{33,34}$ Christen (1968), Feistner \& Price (1991); ${ }^{35}$ M. van Noordwijk \& C. van Schaik (unpubl. data); ${ }^{36-43}$ Thierry et al. (1989), de Waal et al. (1993), Fragaszy et al. (1997, 2004), Westergaard \& Suomi (1997), Westergaard et al. (1998, 1999), de Waal (2000); 44${ }^{46}$ Perry \& Rose (1994), Rose (1997, 2001); ${ }^{47-49}$ Feistner \& Ashbourne (1994), Winn (1994), Krakauer \& van Schaik (2005); ${ }^{50,51}$ Nash (1991, 1993); ${ }^{52}$ Watts (1985); ${ }^{53}$ Nowell \& Fletcher (2006); ${ }^{54-59}$ Carpenter (1940), Berkson \& Schusterman (1964), Ellefson (1968), Fox (1972), Schessler \& Nash (1977), Nettelbeck (1998); ${ }^{60-70}$ Wilson (1976), Brown \& Mack (1978), Hoage (1982), Price \& Feistner (1993), Rapaport (1999, 2001, 2006), Ruiz-Miranda et al. (1999), Rapaport \& Ruiz-Miranda (2002, 2006), Tardif et al. (2002); ${ }^{71}$ Bertrand (1969); ${ }^{72,73}$ Kummer \& Cords (1991), M. van Noordwijk (pers.comm.); ${ }^{74,75}$ Hikami et al. (1990), Matusbara \& Funakoshi (2001); ${ }^{76}$ Fan \& Jiang (2009); ${ }^{77}$ Zimmermann (1989); ${ }^{78-87}$ Kano (1980), Badrian \& Badrian (1984), Badrian \& Malenky (1984), Kuroda (1984), de Waal (1992), Hohmann \& Fruth (1993, 2008), White (1997), Fruth \& Hohmann (2002), Surbeck \& Hohmann (2008), Jaeggi et al. (2010); ${ }^{88-136}$ Nissen \& Crawford (1936), van Lawick-Goodall (1968), Nishida (1970, 1983), Suzuki (1971), Teleki (1973), McGrew (1975), Wrangham (1975), Silk (1978, 1979), Nishida et al. (1979, 1992), Tutin (1979), Kawanaka (1982), Takahata et al. (1984), Goodall (1986), Boesch \& Boesch-Achermann (1989, 2000), de Waal (1989, 1992, 1997), Hiraiwa-Hasegawa (1990a,b), 
Boesch (1994), Kuroda et al. (1996), Nishida \& Turner (1996), Hemelrijk et al. (1999), Mitani \& Watts (1999, 2001), Newton-Fisher (1999), Stanford (1999), Bethell et al. (2000), Nakamura \& Itoh (2001), Hunt \& McGrew (2002), Matsumoto-Oda (2002), Watts \& Mitani (2002), Hirata \& Celli (2003), Ueno \& Matsuzawa (2004), Stevens (2004), Reynolds (2005), Slocombe \& Newton-Fisher (2005), Gilby (2006), Lonsdorf (2006), Mitani (2006), Hockings et al. (2007), Pruetz \& Bertolani (2007), Gomes \& Boesch (2009), Gilby et al. (2010), Jaeggi et al. (2010); ${ }^{137-139}$ Harding (1973), Strum $(1975,1981) ;{ }^{140}$ Starin (2006); ${ }^{141}$ Homburg (1997); ${ }^{142-144}$ Utami \& van Hooff (1997), van Noordwijk \& van Schaik (2009), Forss et al. (2009); ${ }^{145-149}$ Horr (1977), Bard (1987, 1992), Jaeggi et al. (2008), van Noordwijk \& van Schaik (2009); ${ }^{150}$ Kavanagh (1972); ${ }^{151-153}$ Cebul \& Epple (1984), Yoneda (1984), Goldizen (1989); ${ }^{154,155}$ Heymann (1996), Huck et al. (2004); ${ }^{156}$ Izawa (1978); ${ }^{157-168}$ Wolters (1978), Neyman (1989), Cleveland \& Snowdon (1984), Feistner \& Chamove (1986), Feistner \& Price (1990, 1991, 1999), Savage et al. (1996), Roush \& Snowdon (2000, 2001), Joyce \& Snowdon (2007), Humle \& Snowdon (2008) $;{ }^{169,170}$ Fragaszy \& Mason (1983), Stevens (2004); ${ }^{171}$ Jay (1965); ${ }^{172}$ Fox (1972);

${ }^{173}$ Gursky (2000) 
TABLE 2: Contingency table showing the distribution of species in Table 1 across food sharing contexts and our predictor variables, as well as Fisher's exact tests for the association of these variables

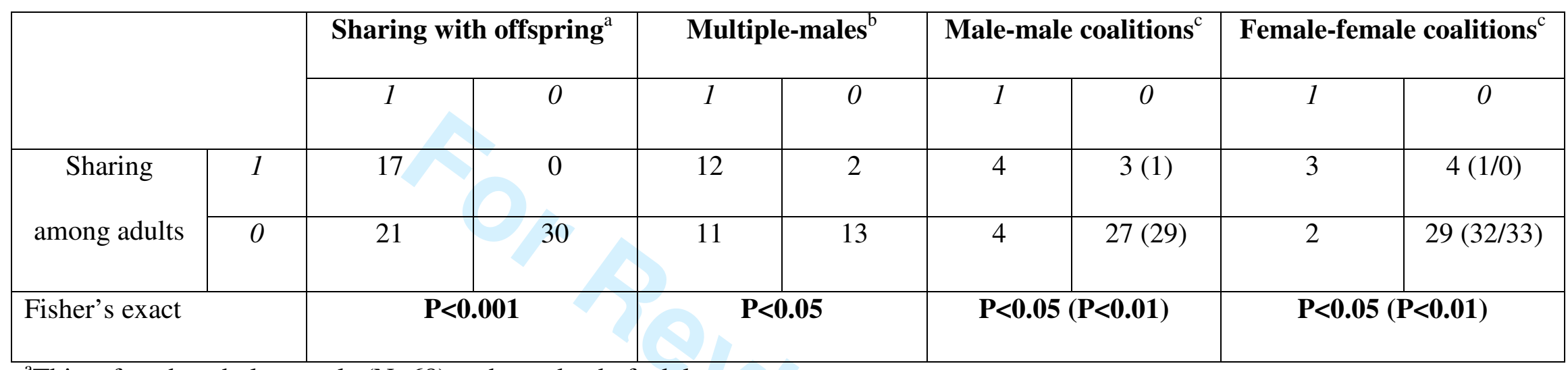

${ }^{\mathrm{a}}$ This refers the whole sample $(\mathrm{N}=68)$ and any dyad of adults

${ }^{\mathrm{b}}$ Multi-male species vs. single-male species; this refers to male-female sharing in species already sharing with offspring $(\mathrm{N}=38)$

${ }^{\mathrm{c}}$ This refers to male-male and female-female sharing respectively, in species already sharing with offspring $(\mathrm{N}=38)$. The numbers in parentheses refer to sharing only among non-kin (for females Pygathrix nemaeus assumed to be non-kin/kin) 
TABLE 3: Overview of the comparative analyses testing for correlated evolution of food sharing and other traits, and the support for the related hypotheses. Significant factors are bold

\begin{tabular}{|c|c|c|c|c|c|c|}
\hline Food sharing & $\mathbf{N}$ & Factors & $\mathbf{G E E}^{\mathbf{a}}$ & RJ MCMC & Related hypotheses & Supported? \\
\hline \multirow[t]{4}{*}{ with offspring } & 68 & Intercept & -1.03 & & & \\
\hline & & Extractive foraging & $1.86^{*}$ & & Informational hypothesis & + \\
\hline & & Diet quality index (DQI) & 0.86 & & Nutritional hypothesis & - \\
\hline & & Extractive foraging ${ }^{*} \mathrm{DQI}$ & $-2.32^{*}$ & & & - \\
\hline \multirow{4}{*}{$\begin{array}{l}\text { among adults } \\
\text { (any sex } \\
\text { combination) }\end{array}$} & 68 & Intercept & -2.84 & & & \\
\hline & & Sharing with offspring & $1.35 * * *$ & $P_{\text {ind }}=0, B F=30.94$ & Constraint / Precondition & +++ \\
\hline & & Extractive foraging & 0.38 & & & - \\
\hline & & DQI & -0.49 & & & - \\
\hline from males to & 38 & Intercept & -1.87 & & & \\
\hline females $^{c}$ & & Multi-male groups & $1.96^{*}$ & $\mathrm{P}_{\text {ind }}=0.004, \mathrm{BF}=3.9$ & Female mate choice & + \\
\hline
\end{tabular}


("Food for sex")

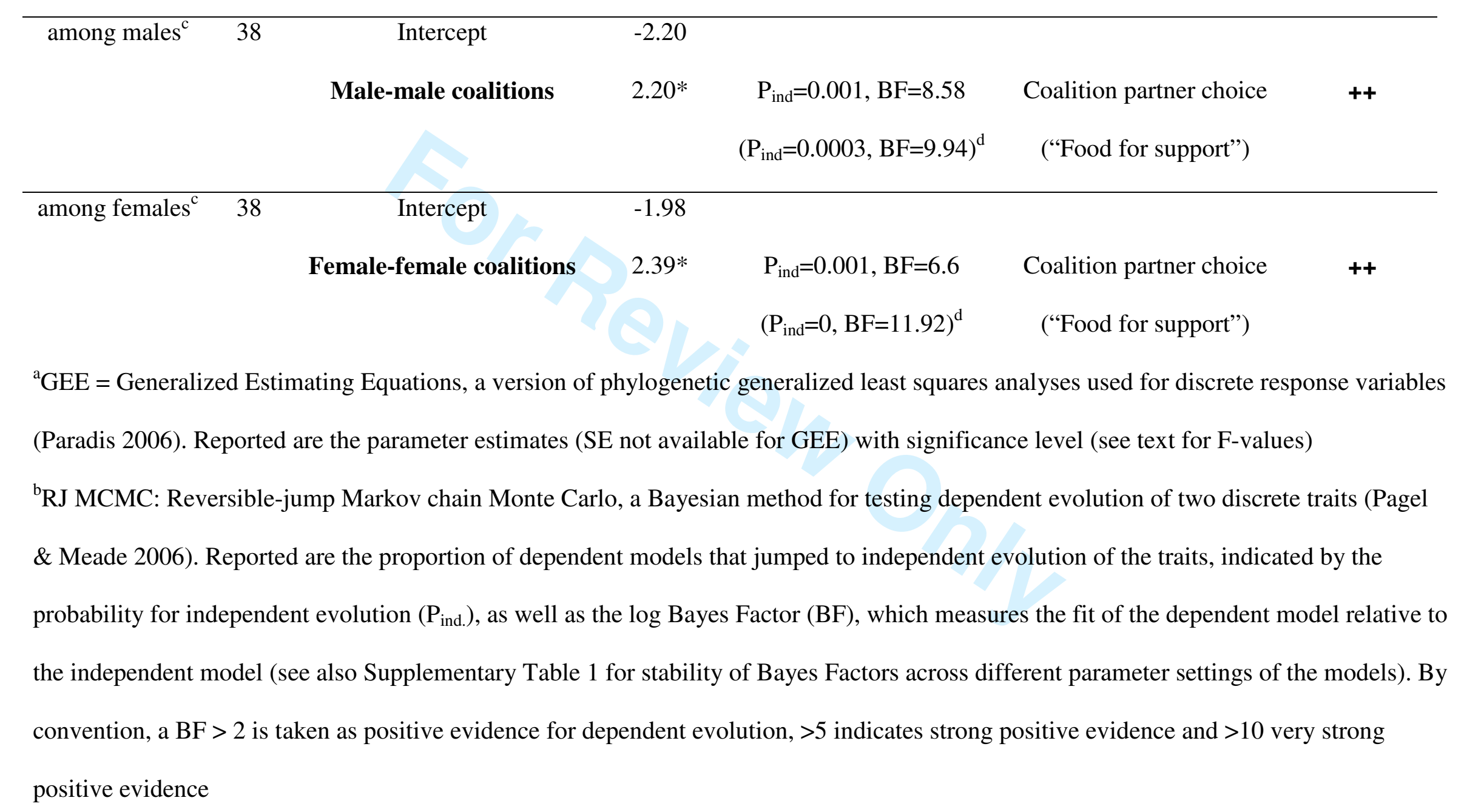


${ }^{\mathrm{c}}$ Only species in which there is food sharing with offspring

${ }^{\mathrm{d}}$ The values in parentheses refer to the analyses restricted to sharing among nonkin

$* * *: \mathrm{P}<0.001, *: \mathrm{P}<0.05$ 


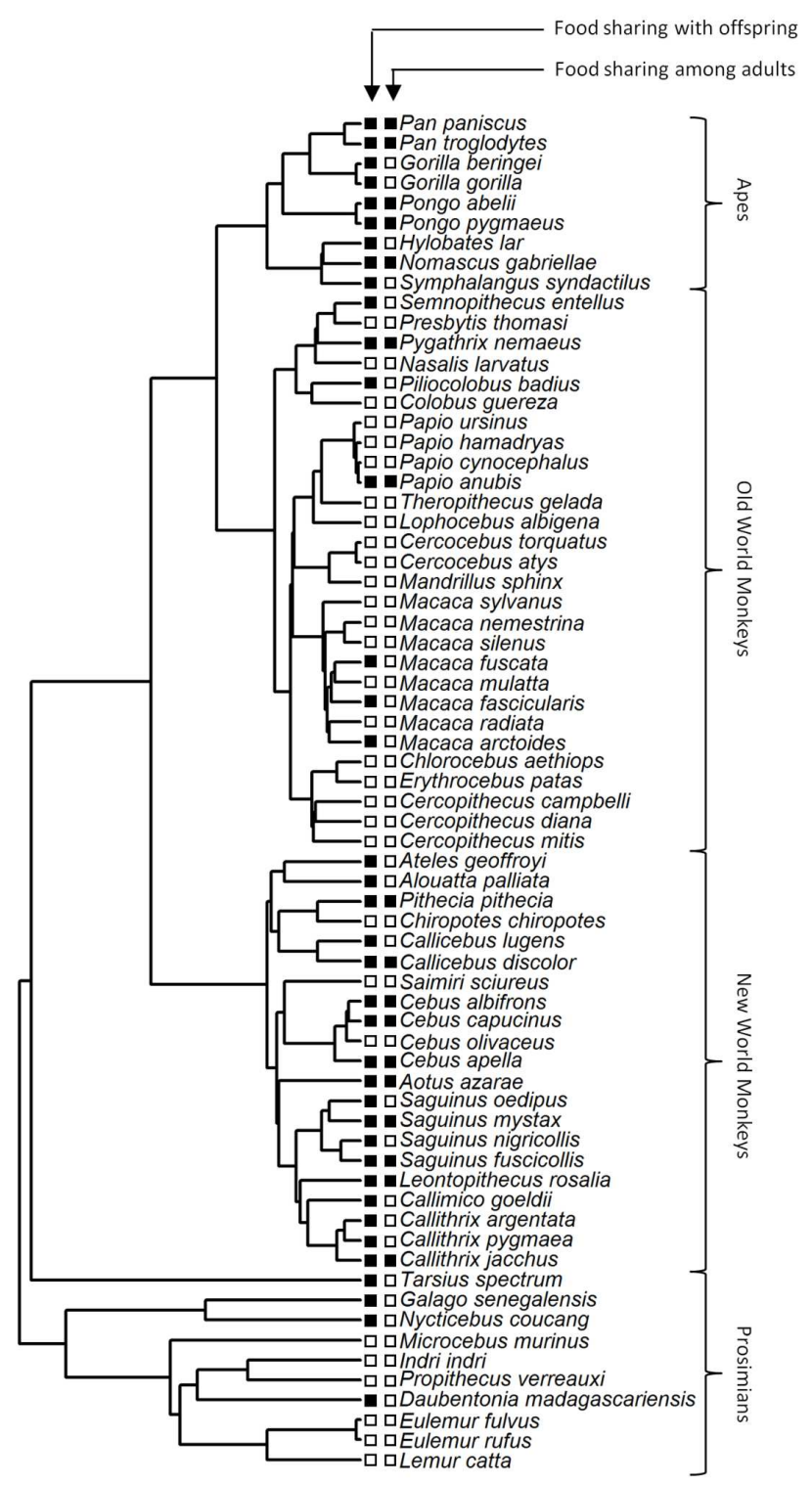

The phylogenetic tree, based on Bininda-Emonds et al. (2007), of the 68 species in our sample representing all major taxonomic groups of primates (see Table 1). The traits "food sharing with offspring" and "food sharing among adults" are marked as present (black) or absent (white) $195 \times 357 \mathrm{~mm}(300 \times 300 \mathrm{DPI})$ 


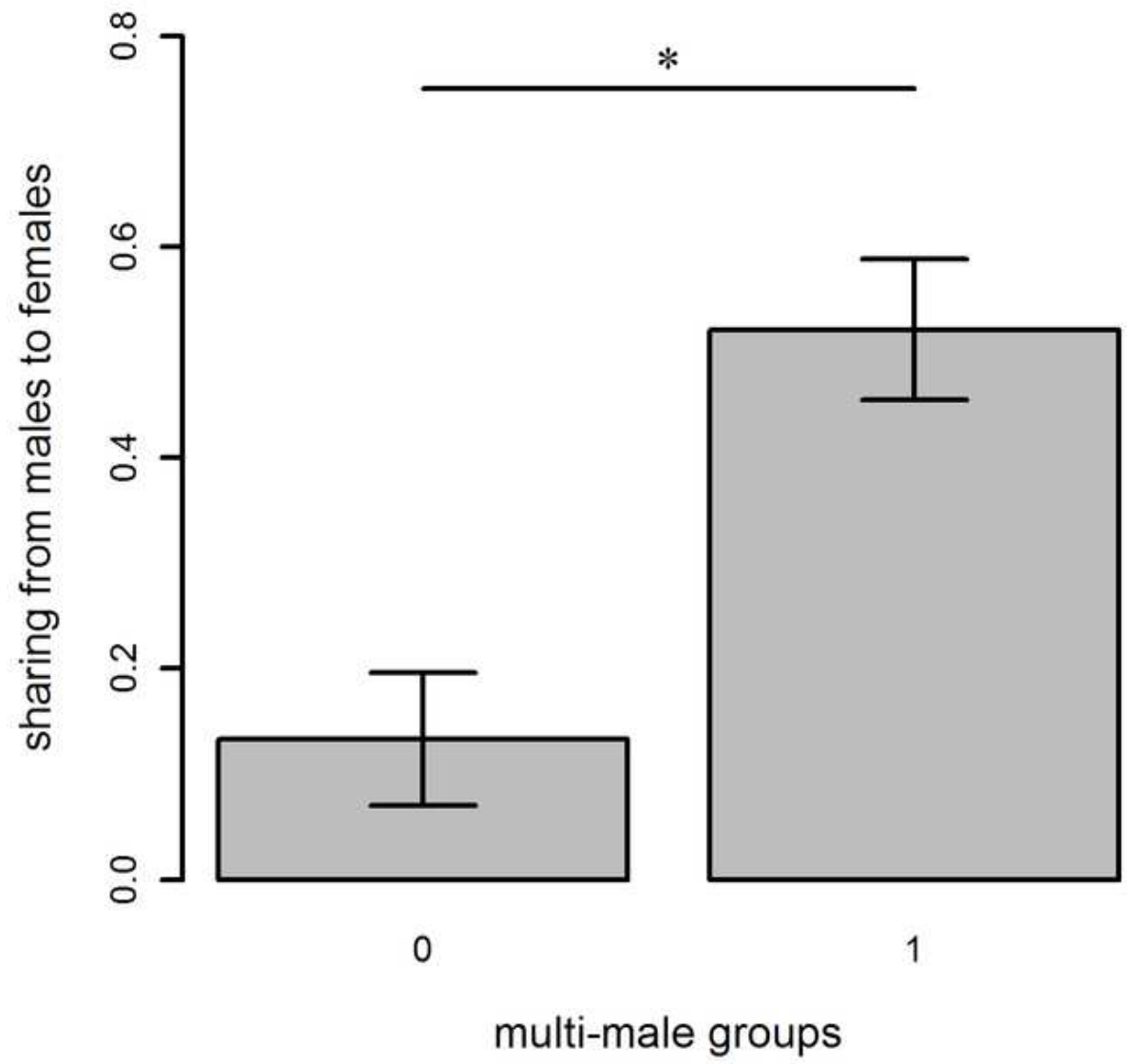

Mean ( \pm SEM) occurrence of food sharing a) from males to females, b) among males and c) among females, in species in which a) multi-male groups, b) male-male coalitions and c) female-female coalitions are absent (0) or present (1). In all cases, the occurrence of food sharing is significantly higher in species in which the traits are present. The significance values $(*: P<0.05)$ refer to the respective GEE models (Table 2 )

$59 \times 59 \mathrm{~mm}(300 \times 300 \mathrm{DPI})$ 


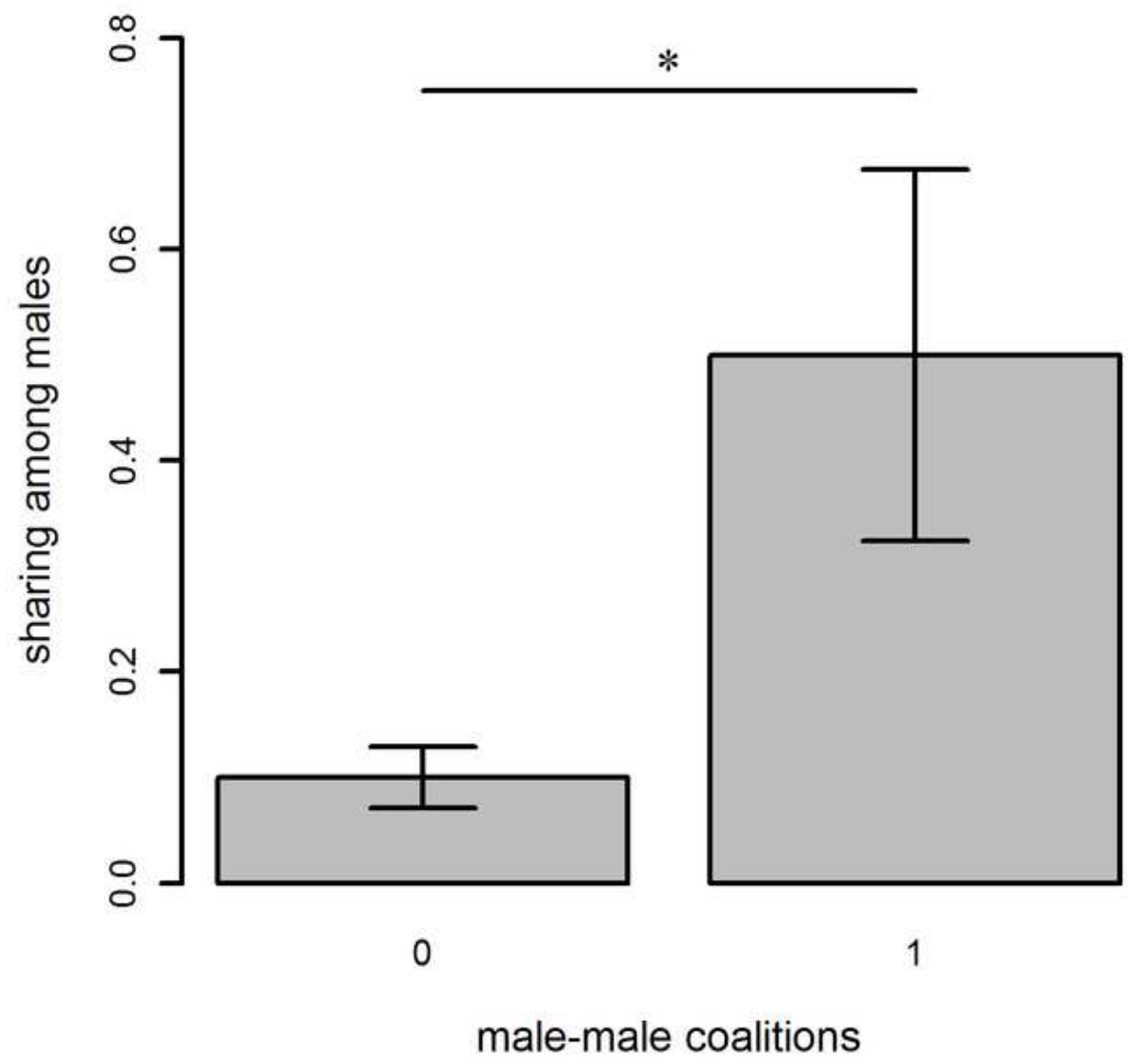

Mean ( \pm SEM) occurrence of food sharing a) from males to females, b) among males and c) among females, in species in which a) multi-male groups, b) male-male coalitions and c) female-female coalitions are absent (0) or present (1). In all cases, the occurrence of food sharing is significantly higher in species in which the traits are present. The significance values $(*: P<0.05)$ refer to the respective GEE models (Table 2$)$

$59 \times 59 \mathrm{~mm}(300 \times 300 \mathrm{DPI})$ 


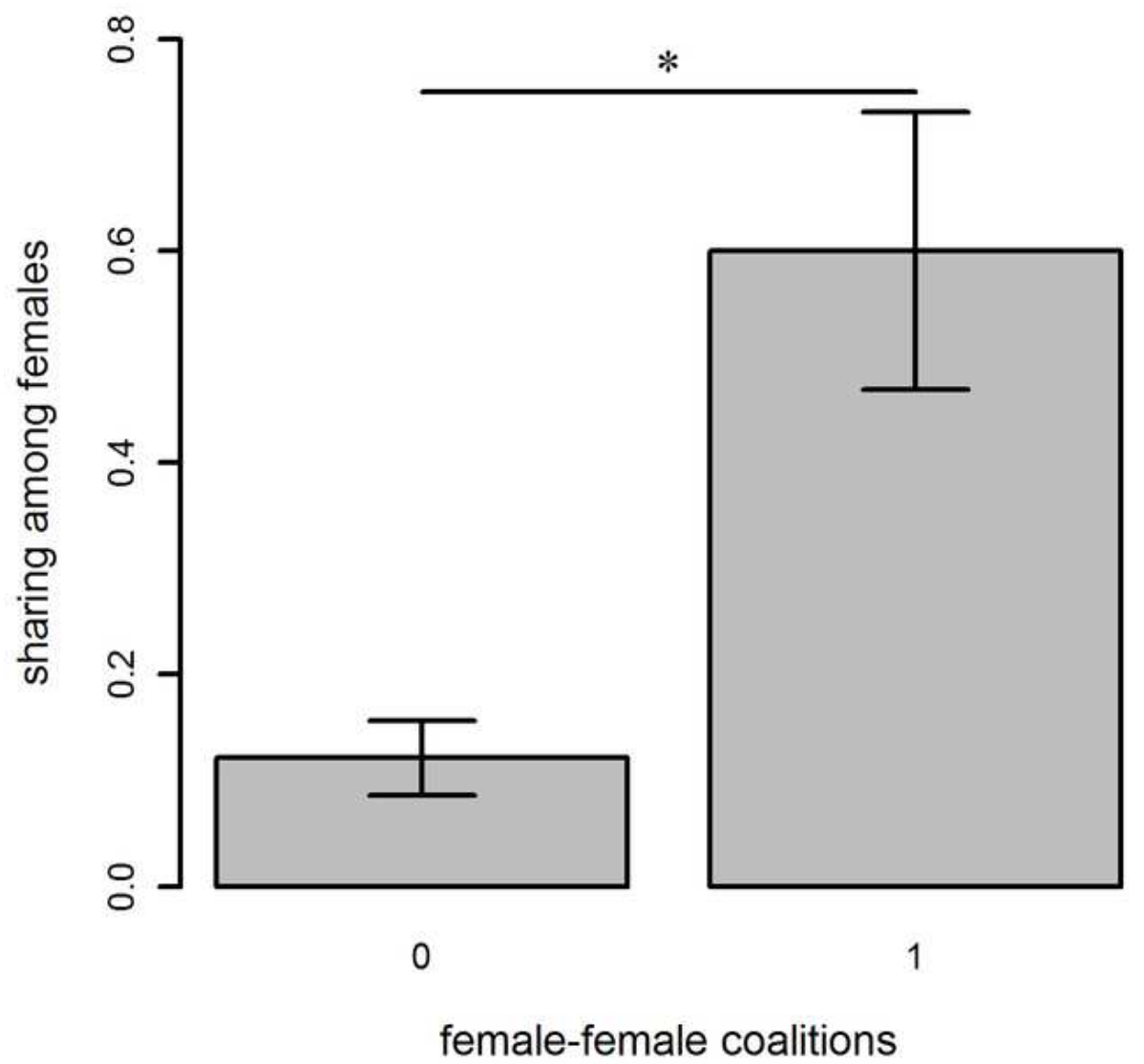

Mean ( \pm SEM) occurrence of food sharing a) from males to females, b) among males and c) among females, in species in which a) multi-male groups, b) male-male coalitions and c) female-female coalitions are absent (0) or present (1). In all cases, the occurrence of food sharing is significantly higher in species in which the traits are present. The significance values $(*: P<0.05)$ refer to the respective GEE models (Table 2 )

$59 \times 59 \mathrm{~mm}(300 \times 300 \mathrm{DPI})$ 


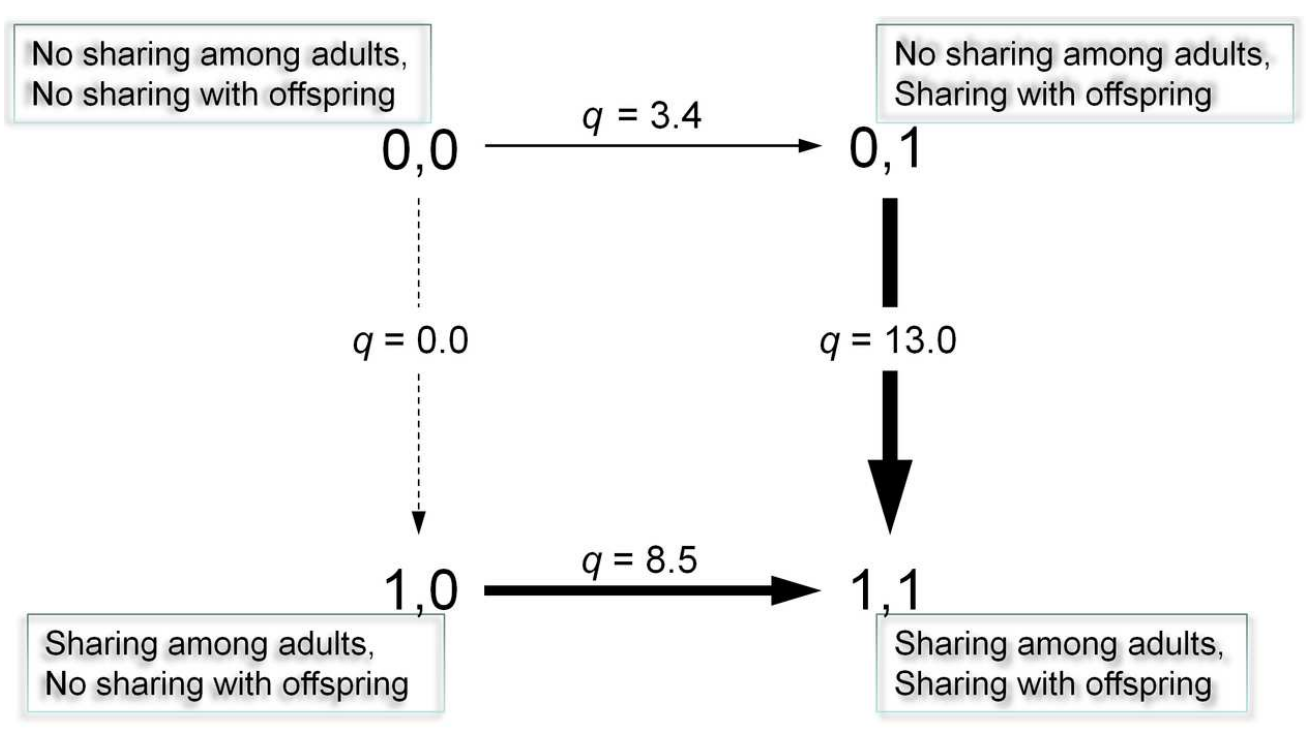

Flow charts for the evolution of food sharing among adults (first trait) in the presence or absence of a) food sharing with offspring and b) opportunities for partner choice (second traits), as analyzed with the RJ MCMC method. The thickness of the arrows is proportional to the mean value of the rate parameters $\mathrm{q}$ in the posterior sample and thus indicates the likelihood of the transition from one state to another. By comparing opposite arrows it can clearly be seen that the evolution of sharing among adults is much more likely if a) sharing with offspring or b) opportunities for partner choice is already present as a trait (and vice versa, although sharing among adults is unlikely to evolve first). The values of $q$ in $b$ ) are the means of the sex-combination specific analyses, i.e. malefemale, male-male and female-female sharing, and multi-male groups, male-male coalitions and female-female coalitions respectively (see Online Resources 1 for full details). Note that a) is based on 68 species while b) is based on only 38 species, namely those in which sharing with offspring was already present, and only refers to sharing among unrelated adults. Furthermore, note that only the arrows for evolutionary gains of traits are represented, the ones for losses were omitted in this figure (but not in the analyses, see Online Resources 1 ) because we here assume the ancestral state to be 0,0 $106 \times 58 \mathrm{~mm}(300 \times 300$ DPI $)$ 


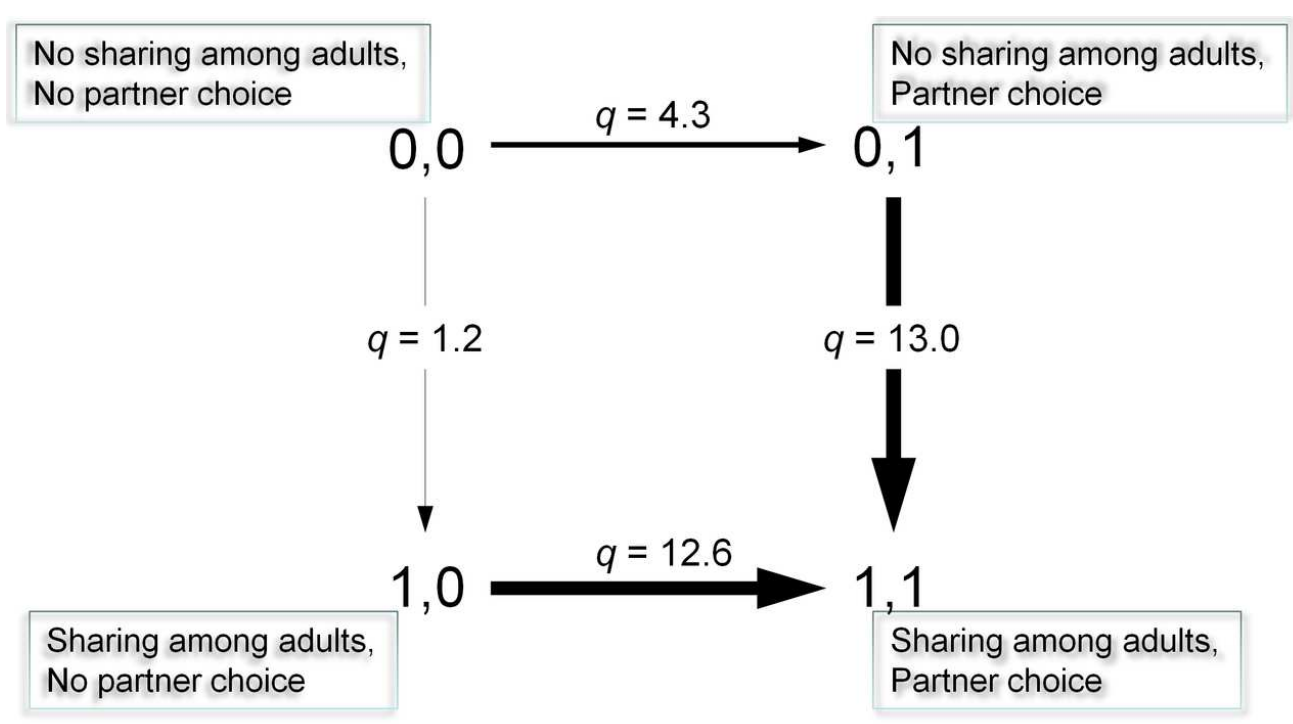

Flow charts for the evolution of food sharing among adults (first trait) in the presence or absence of a) food sharing with offspring and b) opportunities for partner choice (second traits), as analyzed with the RJ MCMC method. The thickness of the arrows is proportional to the mean value of the rate parameters $\mathrm{q}$ in the posterior sample and thus indicates the likelihood of the transition from one state to another. By comparing opposite arrows it can clearly be seen that the evolution of sharing among adults is much more likely if a) sharing with offspring or b) opportunities for partner choice is already present as a trait (and vice versa, although sharing among adults is unlikely to evolve first). The values of $q$ in $b$ ) are the means of the sex-combination specific analyses, i.e. malefemale, male-male and female-female sharing, and multi-male groups, male-male coalitions and female-female coalitions respectively (see Online Resources 1 for full details). Note that a) is based on 68 species while b) is based on only 38 species, namely those in which sharing with offspring was already present, and only refers to sharing among unrelated adults. Furthermore, note that only the arrows for evolutionary gains of traits are represented, the ones for losses were omitted in this figure (but not in the analyses, see Online Resources 1 ) because we here assume the ancestral state to be 0,0

$107 \times 59 \mathrm{~mm}(300 \times 300 \mathrm{DPI})$ 


\section{EVOLUTION OF FOOD SHARING}

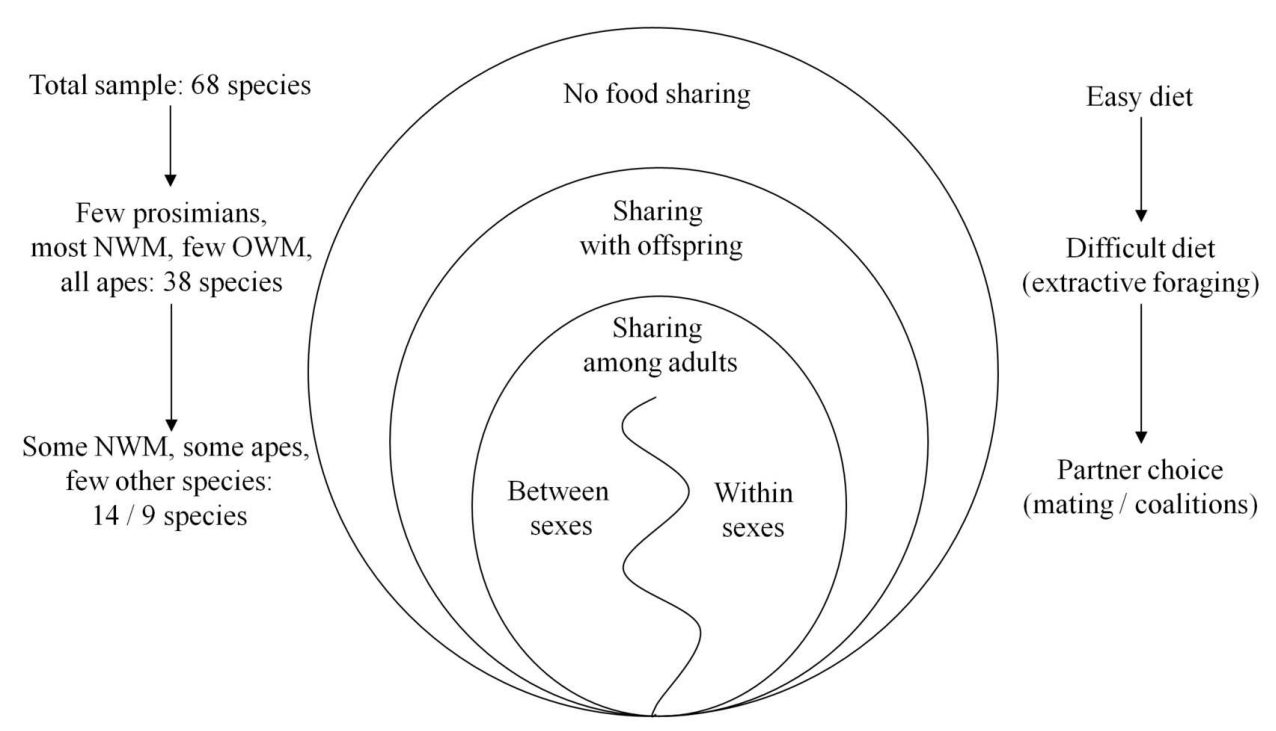

This figure summarizes our findings on the evolution of food sharing in primates: Of the 68 species in the total sample, sharing with offspring evolved in the subset of those with relatively difficult diets, as measured by the degree of extractive foraging, indicating differential acquisition of food by adults and offspring and thus high benefits to sharing. Within those 38 species sharing food with offspring, sharing among adults was more likely to evolve in the subset of species with opportunities for partner choice, indicating that food is shared in order to increase (or not decrease) the chance of future matings (between sexes) or coalitionary support (within sexes). NWM = New World monkeys, OWM $=$ Old World monkeys $147 \times 97 \mathrm{~mm}$ (300 x 300 DPI) 